\title{
Lancelot en Olite: paradigmas arquitectónicos y referentes literarios en los palacios de Carlos III de Navarra (1387-1425)
}

\author{
Javier MARTíneZ DE AguirRe \\ Universidad Complutense de Madrid \\ Departamento de Historia del Arte I (Medieval) \\ jmtzagui@ucm.es
}

\begin{abstract}
RESUMEN
Este estudio examina en qué medida la renovadora distribución de estancias de los palacios regios franceses de tiempos de Carlos V el Sabio (Vincennes y el Louvre) y la constitución de un núcleo torreado residencial en Aviñón pudieron servir de referente en la ampliación del palacio de Olite por encargo de Carlos III de Navarra (1387-1425). La segunda fase de obras (1411-1420) incluyó edificaciones de formas caprichosas, para las que no se han identificado modelos ultrapirenaicos. El autor propone para ellas una explicación a partir de contextos literarios (pasajes del Lanzarote del Lago), de la personalidad del soberano y de las vicisitudes del reinado. La documentación avala la participación directa del rey en el proyecto del palacio y la alta valoración que las empresas arquitectónicas tenían en su concepción de la realeza.
\end{abstract}

Palabras clave: Palacio de Olite, Castillo de Olite, Carlos III de Navarra, Lanzarote del Lago, Vincennes, Louvre, Aviñón, Castillo de Tudela, arquitectura gótica navarra.

\section{Lancelot in Olite: architectural paradigms and literary references in the palaces of Charles III of Navarre (1387-1425)}

\begin{abstract}
This paper examines to what extent the new distribution of rooms in royal French palaces at the time of Charles V, the Wise (Vincennes and Le Louvre), and the constitution of a residential complex with towers in the Papal Palace in Avignon, served as models for the enlargement of the Royal Palace of Olite commissioned by Charles III, King of Navarre (1387-1425). The second phase of the works (1411-1420) included buildings in fanciful shapes, for which French patterns have not been identified. The author proposes for them an explanation based on literary references (the Prose Lancelot), the personality of the King and the vicissitudes of his reign. Documentation proves the King's direct supervision over the palace project and the high regard that architectural enterprises had in his own regard of royalty.
\end{abstract}

Key words: Royal Palace of Olite, Castle of Olite, Charles III King of Navarre, Lancelot du Lac, Vincennes, Avignon, Castle of Tudela, Gothic architecture of Navarre. 


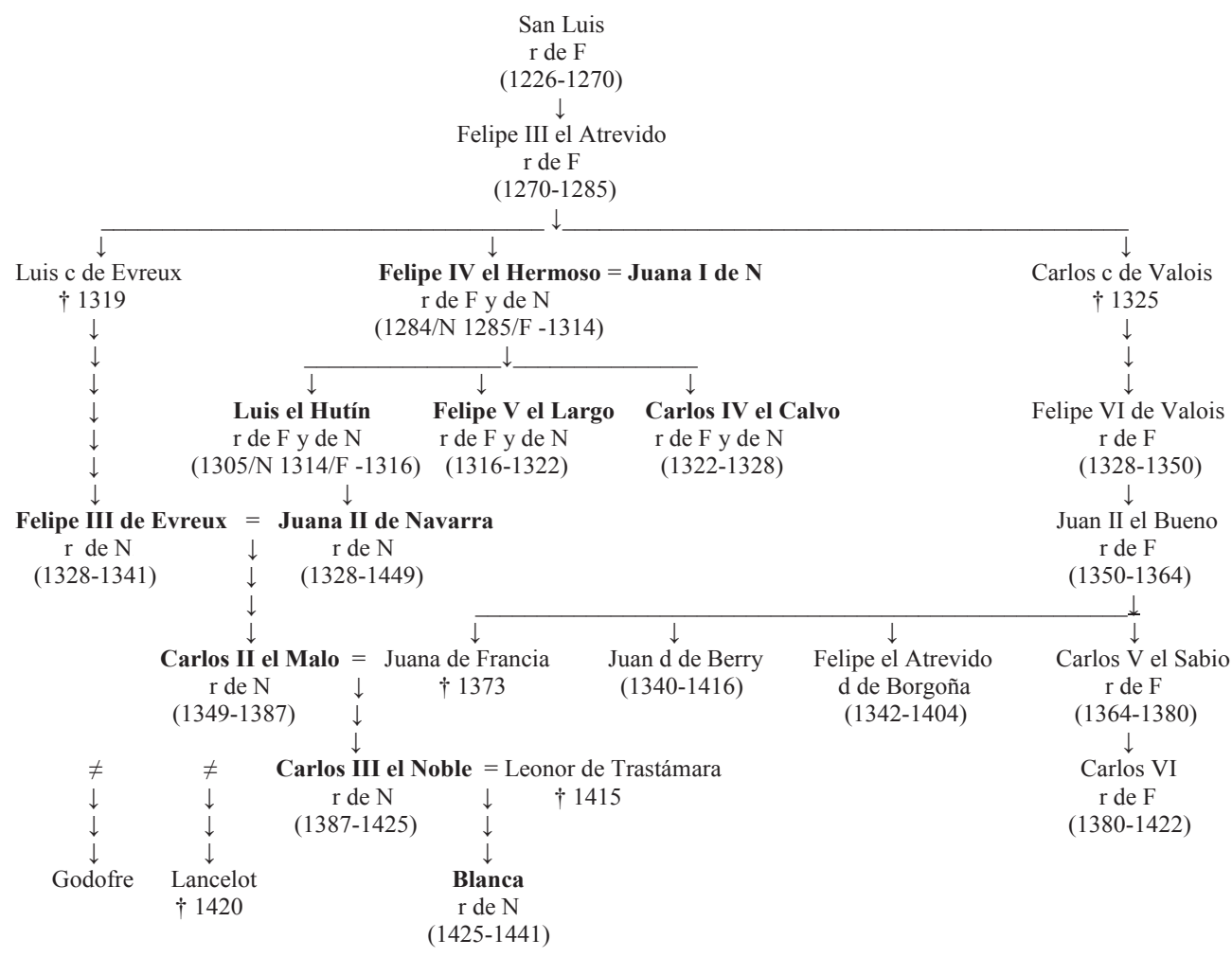

Fig. 1. Árbol genealógico de Carlos III de Navarra (r: rey; d: duque; c: conde; F: Francia; $\mathrm{N}$ : Navarra; =: matrimonio; $\neq$ relación extramatrimonial).

1 de enero de 1387. Carlos II acaba de fallecer en su palacio de Pamplona. Su hijo y heredero, el futuro Carlos III el Noble (1361-1425), recibe la noticia en Peñafiel y emprende el regreso ${ }^{1}$. El joven rey no se instalará definitivamente en el palacio de la capital, edificado doscientos años atrás por Sancho VI el Sabio. Pese a las remodelaciones emprendidas por sus padres, ni la distribución ni su simplicidad arquitectónica eran adecuadas al modo de vida que había conocido en las residencias parisinas de

1 Sobre Carlos III sigue siendo fundamental el acopio documental de J.R. CASTRO, Carlos III el Noble rey de Navarra, Pamplona, 1967. La significación de su reinado para la historia navarra en J.M. LACARRA, Historia del reino de Navarra, Pamplona, 1973, III, pp. 161-217. Con intención divulgativa: B. LEROY y E. RAMÍREZ VAQUERO, Carlos III el Noble Rey de Navarra, Pamplona, 1991. Con planteamientos renovadores, de los que aquí interesan especialmente las relaciones con los Valois: E. RAMÍREZ VAQUERO, Carlos III rey de Navarra Príncipe de sangre Valois (1387-1425), Gijón, 2007. Aportaciones recientes sobre la corte del rey: M. NARBONA CÁRCELES, La corte de Carlos III el Noble, rey de Navarra: espacio doméstico y escenario del poder, 1376-1415, Pamplona, 2006, autora que también ha publicado sobre la capilla, representaciones del rey, música, encargos literarios, heraldos, juglares, divisas regias, etc.; E. Ramírez Vaquero ha investigado, entre otras cuestiones, la diplomacia, la hacienda y el patrimonio regios; F. Lárrayoz la cocina y el régimen alimentario, vajilla, viajes, práctica de la medicina, etc.; y M. Osés Urricelqui los rituales de la realeza. 
su tío Carlos V y su primo Carlos VI (fig. 1) mientras estuvo retenido entre 1378 y $1381^{2}$. Ciertamente podría haberlo reconstruido o ampliado a su gusto, como pronto haría en otros lugares, pero quizá le frenó el litigio sobre la propiedad, reivindicada por la corona y la mitra durante siglos ${ }^{3}$. Las temporadas pasadas en Castilla le habrían llevado a apreciar la bondad de tierras soleadas y apacibles, como la Ribera Alta de Olite o la Ribera de Tudela, donde había residido Sancho VII y donde los Teobaldos habían financiado la conclusión de la catedral. Los palacios de ambas localidades no tardaron en ser objeto de mejora.

En 1388 Carlos III compra casas en Olite para ampliar el acceso del palacio, en lo que será el germen de la actual plaza de los Teobaldos. Al año siguiente repara la cámara del rey, construye detrás de ella un retrait (aposento privado) doble, mejora la gran cámara de las damas, la bodega y la torre, y decora las estancias con pinturas ${ }^{4}$. En Tudela entre marzo de 1388 y enero de 1391 acomete una remodelación sustancial del castillo. Ordena edificar una cámara sobre la puerta con dos chimeneas y seis ventanas vidriadas, y a su lado un gran comedor enladrillado con chimenea, grada de alabastro para la mesa del rey y techo de madera cubierto de "ladrillos enclavados" decorados con los escudos de Francia y Navarra. Encarga renovar la cocina, con cinco chimeneas, y la frutería aneja. La nueva distribución permite acceder desde el comedor a las galerías "a manera de claustra por tal que las gentes puedan andar por cubierto". Las que daban al huerto del castillo contaban con suelo de ladrillos pintados y alabastro, y con ventanas donde fueron "figurados todos los reyes et emperadores cristianos e otras cosas". La cámara denominada del Bel Regart, sobre la torre de la capilla de Santa María y dotada de ventanas de vidrio y alabastro, quedaba al lado del retrait. Diez manzanas de oro colgantes embellecían la cámara de don Carlos, iluminada por ventanas de alabastro "obrado e figurado". Una galería alta ("andamio") conducía a la torre del guardarropa. De la habitación sobre la cámara del rey se pasaba a una gran sala pintada con castaños; su alfarje "a manera de cubos", apoyaba en tres arcos de madera de los que pendían castañas de oro. Como en Vincennes, inmediato a la capilla estaba el oratorio del rey.

Esta somera descripción de espacios de los que nada ha quedado es posible gracias a las indicaciones contenidas en los registros de cuentas ${ }^{5}$. Destacaremos cuatro aspectos comunes a la mayor parte de los palacios de Carlos III. Primero, que la naturaleza de las obras consistió en la remodelación de una edificación preexistente. Se-

2 El infante habría frecuentado Vincennes. Constan dos estancias: J.M. LACARRA, op. cit., 1973, III, p. 137. Sobre la dimensión artística de sus viajes a París: J. MARTÍNEZ DE AGUIRRE, "La rueda de la Fortuna: Carlos III el Noble de Navarra (1387-1425) en París, de rehén a promotor de las artes", El intercambio artístico entre los reinos hispanos y las cortes europeas en la Baja Edad Media, León, 2009, pp. 379-405. Sobre los viajes también F. BOZANO GARAGORRI, "Itinerarios en Francia del rey Carlos III", Estudios sobre la realeza navarra en el siglo XV, Pamplona, 2005, pp. 129-178.

3 J. MARTÍNEZ DE AGUIRRE y J. SANCHO, "El Palacio Real durante la Edad Media", El Palacio Real de Pamplona, Pamplona, 2004, pp. 19-26.

4 Sobre la promoción artística del rey: J. MARTÍNEZ DE AGUIRRE, Arte y monarquía en Navarra 13281425, Pamplona, 1987; el palacio de Olite en pp. 139-185; las obras de 1388-1389 en pp. 146-147.

5 Resume las obras de Tudela: J. MARTINEZ DE AGUIRRE, op. cit., 1987, pp. 202-206. Los datos proceden principalmente del Archivo General de Navarra, Sección de Comptos, Reg. 209, parcialmente transcritas por I.B., "Sobre el castillo de Tudela", Príncipe de Viana, VII (1946), pp. 594-597. 
gundo, que la distribución encadenaba, probablemente de menor a mayor privacidad, estancias concebidas para diferentes actividades de la realeza (despachar asuntos, recibir enviados, festejar y compartir el tiempo con sus allegados, recrearse mediante la contemplación visual, rezar, leer, retirarse a espacios recoletos, etc.), mayoritariamente ubicadas en el piso noble. Tercero, que no escatimó medios para embellecerlo y dotarlo de exorno figurativo o emblemático relacionado con asuntos religiosos, con el imaginario de las monarquías europeas o con su propio linaje. Y por último, que para esta obra inicial recurrió a artistas hispanos, dirigidos por el navarro Juan García de Laguardia, maestro de obras del rey, bajo cuyas órdenes trabajaron canteros navarros y castellanos, carpinteros moros de la Ribera, pintores y vidrieros locales, etc., empleando materiales autóctonos o, como la cerámica, importados de Aragón. Algunas jornadas intervinieron más de cien personas. Ahora bien, aunque podamos ensayar la restitución gráfica de esos espacios, la materialidad de la empresa tudelana se nos escapa.

En cambio, el Palacio de Olite pone ante nuestros ojos, herido por transformaciones, destrucciones y restauraciones, uno de los complejos residenciales más relevantes de Occidente hacia 1400. Publicaciones de las últimas décadas han conseguido poner en orden las abundantísimas referencias documentales a torres y estancias, aproximar a cuál de las habitaciones actualmente existentes se corresponden (o bien emplazarlas a partir de vestigios) y recuperar el hilo del proceso constructivo ${ }^{6}$. En paralelo, durante los pasados veinte años se ha profundizado en el estudio de las novedosas fórmulas de distribución de aposentos de las residencias de los Valois. El primero de los objetivos de este estudio consiste en examinar en qué medida esta renovadora ordenación "a la francesa" sirvió de referente a la hora de acometer la ampliación del palacio navarro. Como veremos, en una segunda fase de obras (14111420) elevaron en Olite edificaciones de formas caprichosas, para las que no se han identificado modelos ultrapirenaicos. Su análisis y la propuesta de una explicación a partir de referentes literarios, de la personalidad del soberano y de las vicisitudes del reinado constituyen nuestro segundo objetivo.

\section{La adaptación de paradigmas franceses en la fase inicial del Palacio de Olite}

A partir de la muerte de Sancho el Fuerte se sucedieron en el trono navarro las dinastías champañesa (1234-1284), capeta (1284-1328) y Evreux (desde 1328), cuyos miembros priorizaron sus intereses en territorio francés. Sus estancias en Navarra, breves y espaciadas, apenas requirieron la construcción de nuevos ámbitos residenciales y de poder. El castillo de Tiebas, a $15 \mathrm{~km}$ de Pamplona, fue la excepción. Con

6 Destacan en este sentido J. MARTÍNEZ DE AGUIRRE, op. cit., 1987; A. IRIARTE, "Algunas observaciones acerca del Palacio Real de Olite", Ondare. Cuadernos de Artes Plásticas y Monumentales, 15 (1996), pp. 331-340; y "Los palacios dorados de nuestro señor el rey don Carlos", Tercer Congreso General de Historia de Navarra, Pamplona, 1998. 
él Teobaldo II (1254-1270) introdujo en el reino soluciones parisinas del siglo XIII? De plano regular y distribución tendente a la simetría, en torno a un patio rectangular flanqueado por escaleras intramurales se repartían aposentos de diferentes dimensiones, incluida la cámara "secreta", la bodega con hornacinas y sobre ella una espaciosa sala (de 21,8 por $8,8 \mathrm{~m}$ ) con chimenea y nueve ventanas repartidas en tres de sus muros, que contó con pavimento de azulejos probablemente importados del Norte de Francia.

La situación cambió con el asentamiento definitivo de Carlos II en Navarra a partir de 1361. La remodelación del Palacio de Pamplona, emprendida en 1366 para alojar a la reina Juana (esposa de Carlos II y hermana de Carlos V de Francia), transformó los vetustos aposentos de finales del siglo XII, consistentes en grandes salas, pórticos, bodega y torre, para adecuarlos a las nuevas necesidades de la monarquía. Los documentos citan cámaras diversificadas, guardarropas, oratorio, retrait, baños, letrinas y cuartos de guardia. Las condiciones de vida de las residencias francesas contemporáneas estaban llegando a la corte navarra. Se optó por la adaptación de lo ya construido, mediante labores preferentemente de carpintería, casi sin modificar la apariencia externa del edificio. Como en Tudela, es imposible reconstruir la distribución sobre un plano o recuperar las dimensiones e interconexión de dependencias ${ }^{8}$.

El nuevo paradigma palaciego francés debía mucho a la iniciativa de Carlos V el Sabio (1364-1380). En Vincennes, reordenó formas y usos en el donjon, el châtelet y los aposentos interiores de la cortina, antes de fortificar todo el manoir dentro de un recinto de más de un kilómetro de longitud ${ }^{9}$. En el Louvre impulsó una profunda reorganización, dotándolo de una escalera monumental modélica y poniendo en práctica una novedosa distribución de habitaciones jerarquizadas e interconectadas ${ }^{10}$.

7 M. RAMOS AGUIRRE, "Excavaciones en el castillo de Tiebas (Navarra), primer informe provisional, 1998", Trabajos de Arqueología Navarra (TAN), 15 (2001), pp. 167-213; y "Descubrimiento de un pavimento de baldosas decoradas en el castillo-palacio de Tiebas", TAN, 21 (2009), pp. 317-323.

8 La remodelación del Palacio Real de Pamplona en J. MARTÍNEZ DE AGUIRRE y J. SANCHO, op. cit., 2004, pp. 82-83. Quizá las obras del castillo de Monreal, que frecuentó la reina Juana, lo dotaron con distribución y aspecto semejantes a las residencias francesas; convendría avanzar en el conocimiento de sus ruinas: A. DÍEZ Y DÍAZ, Monreal y su castillo, Pamplona, 1977; J.J. MARTINENA RUIZ, Castillos reales de Navarra (siglos XIII al XVI), Pamplona, 1994, pp. 648-649 y passim; y Navarra. Castillos, torres y palacios, Pamplona, 2008, pp. 178-179; G. CHÁFER REIG, "Una inscripción onomástica en el castillo de Monreal (Navarra)", TAN, 15 (2001), pp. 335-344.

9 La bibliografía sobre Vincennes es abundantísima. Sirva de introducción J. CHAPELOT, Le château de Vincennes. Une résidence royale au Moyen Âge, París 1994, autor que le ha dedicado más de quince publicaciones (varias citadas más adelante). Las modificaciones del programa arquitectónico en J. CHAPELOT, "Le Vincennes des quatre premiers Valois: continuités et ruptures dans un grand programme architectural", Vincennes aux origines de l'État moderne, Paris, 1996, acompañado de estudios de contextualización histórica. Intervenciones arqueológicas recientes recopiladas en: Vincennes. Du manoir capétien à la résidence de Charles V, Les dossiers d'Archéologie, 289 (2003-2004).

10 A. SALAMAGNE, "Le Louvre de Charles V", Le Palais et son Décor. Au temps de Jean de Berry, Tours, 2009, pp. 73-138; M. WHITELEY, “Deux escaliers royaux du XIVe s.: les 'Grands degrez' du Palais de la Cité et la 'Grande Viz du Louvre"”, Bulletin Monumental, 147 (1989), pp. 133-154; y "Royal and Ducal Palaces in France in the Fourteenth and Fifteenth Centuries", Architecture et vie sociale à la Renaissance. L'organisation intérieure des grandes demeures à la fin du Moyen Âge et à la Renaissance, París, 1994a, pp. 47-63 ; y "L'aménagement intérieur des résidences royales et princières en France à la fin du XIVe et au début du XVe siècle", Vincennes aux origines de l'état moderne, París, 1996, pp. 299-303. 
El palacio de Olite, gracias a la excepcional riqueza de las noticias documentales y a la perduración hasta nuestros días de gran parte de las fábricas de sillar, ofrece un campo apropiado para la reflexión acerca del modo como fueron adoptadas estas nuevas pautas ${ }^{11}$. Carlos III concibió su ampliación con la idea de conseguir el marco ideal para la magnificencia de la realeza. Partiendo de un edificio preexistente, el llamado Palacio Viejo (cuyas dependencias fueron progresivamente reacondicionadas), intervino en un primer momento en el área triangular entre dicho palacio, Santa María y el cerco de la villa. Las obras pronto se extendieron al otro lado del templo, siguiendo el cierre amurallado de la población ${ }^{12}$. El conjunto quedó dividido en dos áreas. La distribución previa y las circunstancias topográficas determinaron que el Palacio Viejo fuera destinado a las actividades públicas de la monarquía, incluidas reuniones y recepciones, mientras lo construido al Sur de Santa María se consolidaba como área privada. Se adoptaba así la neta separación espacial entre ámbitos público y privado, que había sido una de las principales novedades de la remodelación del Palais de la Cité parisino en tiempos de Felipe IV (1285-1314), tatarabuelo de Carlos III ${ }^{13}$.

Las nuevas dependencias estaban rodeadas por altos muros sin apenas vanos. El papel de Olite en la defensa de Navarra podía considerarse poco relevante y no existían por entonces amenazas directas hacia la persona del rey o la integridad del reino. ¿Por qué entonces dotar al palacio de apariencia fortificada? Desde luego contribuía a la fortaleza del cierre de la villa, protegía y aislaba la persona y actividades del rey, y fundamentalmente se acomodaba a la "militarización de la vida del soberano", que en opinión de Chapelot constituye "la ruptura más importante que representa el petit chastel" (donjon) de Vincennes ${ }^{14}$. No obstante, no se esforzaron en incrementar la

11 El mayor deterioro del Palacio de Olite vino de los incendios de las guerras de la Convención e Independencia, la rapiña de las ruinas y la intervención restauradora del siglo XX que hoy juzgamos excesiva. La documentación de las obras se conserva en el Archivo General de Navarra: J.R. CASTRO y F. IDOATE, Archivo General de Navarra. Catálogo de la Sección de Comptos, Pamplona, 1959-1974, vols. I-LII. Sobre los avatares del palacio antes y después de 1512: F. IDOATE, "Obras de conservación del Palacio Real de Olite (siglos XVI-XIX)", Príncipe de Viana, XXIX (1968), pp. 237-272. Principales estudios: Diccionario Geográfico-Histórico de España por la Real Academia de la Historia, Madrid, 1802, II, pp. 178-179; J. ITURRALDE Y SUIT, Memoria sobre las ruinas del Palacio Real de Olite, Pamplona, 1870; P. MADRAZO, Navarra y Logroño, Barcelona, 1886, III, pp. 232-254; J.J. YÁRNOZ LARROSA, "La restauración del Palacio Real de Olite", Boletín de la Comisión de Monumentos de Navarra, XVI (1925), pp. 315-376; y "Palacio Real de Olite: restauración de la torre de los Cuatro Vientos", Príncipe de Viana, 2 (1941), pp. 1133; J.R. MARTÍNEZ ERRO, Olite, Corte de Reyes. Apuntes históricos sobre la ciudad de Olite, Pamplona, 1946; J.R. CASTRO, op. cit., 1967, pp. 518-527; J.M. JIMENO JURÍO, Palacio real de Olite, Pamplona, s.a.; J.E. URANGA GALDIANO y F. ÍNIGUEZ ALMECH, Arte medieval navarro, Pamplona, 1975, V, pp. 191211; A. DÍEZ Y DÍAZ, Olite historia de un reino, Estella, 1984; M.C. GARCİA GAINZA et alii, Catálogo Monumental de Navarra. III. Merindad de Olite, Pamplona, 1985, pp. 312-326; J. MARTÍNEZ DE AGUIRRE, op. cit., 1987 y op. cit., 2008; J.R. POZO, Olite trono de un reino. Historia de la restauración, Catálogo de exposición, Pamplona, 1994; A. IRIARTE, op. cit., 1996 y op. cit., 1998; C. JUSUÉ SIMONENA, Palacio real de Olite: sede de un reino, León, 2003; y J. ITURRALDE Y SUIT, A. LAGARDE e I.J. URRICELQUI PACHO, Palacio Real de Olite, 1869, Pamplona, 2006.

12 Para la cronología de las obras: J. MARTÍNEZ DE AGUIRRE, op. cit., 1987 e A. IRIARTE, op. cit., 1998.

13 M. WHITELEY, op. cit., 1994a, p. 48. Quizá en los palacios románicos navarros con dos naves (episcopal y real de Pamplona) existía una diferenciación de esta naturaleza, pero no es posible verificarlo.

14 J. CHAPELOT, "L'hôtel du roi à Vincennes: Charles V dans son logis", La Cour du Prince. Cour de France, cours d'Europe XIIe-XVe siècle, París, 2011, p. 157. El temperamento de Carlos III era en este aspecto 
capacidad defensiva de las cortinas, ya que prescindieron de matacanes o barbacanas (la renovación de dispositivos defensivos fue muy significativa en Vincennes ${ }^{15}$ ).

En el imaginario del rey Noble y sus familiares franceses los grandes palacios, incluso los urbanos, seguían ligados a la arquitectura militar. El entorno parisino hacia 1360-1390 destacó justamente no por la renovación de las formas ornamentales y estructurales de la arquitectura eclesial, sino por los nuevos recursos poliorcéticos con que fueron dotadas las construcciones de Carlos $\mathrm{V}^{16}$. Mientras el infante navarro estuvo retenido en París se encontraba en plena actividad la fortificación del área habitada de Vincennes, con la construcción del impresionante recinto regular jalonado por nueve torres ${ }^{17}$. Claro que Vincennes era la residencia preferida de una monarquía entonces amenazada por los vaivenes de la Guerra de los Cien Años (desde 1369 la protección permanente de Carlos $\mathrm{V}$ estaba confiada a veinte hombres de armas ${ }^{18}$ ). De igual modo, en Aviñón (que Carlos III también conoció personalmente en 1381), desde tiempos de Juan XXII "el papa vivía en una torre fácil de defender donde estaba literalmente sentado sobre su tesoro" 19 . Las ampliaciones de Benedicto XII y Clemente VI lo dotaron de grandes salas de representación y capillas longitudinales, al tiempo que las habitaciones privadas y otros aposentos papales permanecían fieles a la fórmula torreada, con la torre del papa (inicialmente aislada, a manera de donjon) y las del estudio, de las capillas, de Trouillas (de $52 \mathrm{~m}$ de altura), de la campana, de Juan XXII, de la camera cervi, etc. Como constata Gagnière, desde tiempos de Clemente VI "el papado parecía sólidamente establecido, al abrigo de muros elevados y torres imponentes, cuyo número fue todavía aumentado por Inocencio VI quien, por otra parte, envolvió la ciudad con un nuevo recinto" ${ }^{20}$. Otro tanto cabe decir de las residencias de los grandes duques en Saumur, Moulins, Pierrefonds, La Ferté-Milon, Bicêtre, etc. Las miniaturas del calendario de las Muy Ricas Horas del Duque de

muy distinto del de su padre. Durante toda su vida mostró talante pacificador y evitó los enfrentamientos armados, lo que no resta para que, paradójicamente, una y otra vez contratase a armeros de primera categoría de los reinos vecinos (franceses, aragoneses, castellanos, pero también italianos: J. MARTÍNEZ DE AGUIRRE, op. cit. 1987, p. 81) para que le surtieran de arneses de primera categoría. Ni estos encargos implicaban el deseo de participar en combates reales, ni la arquitectura de apariencia militar evidenciaba una previsión de cara a conflictos en el horizonte.

15 N. FAUCHERRE, "Vincennes, la défense de la tour", Bulletin Monumental, 152 (1994), pp. 337-355; y J. CHAPELOT, op. cit., 2011, p. 151. Sobre las almenas de Olite: A. IRIARTE, op. cit., 1996, pp. 336-337. En Olite apenas hay diferencias significativas entre las fachadas que daban al exterior y al interior de la población, luego sus formas no estaban determinadas por la defensa contra ataques enemigos.

16 "La arquitectura militar opera una verdadera revolución adaptándose, como en la Bastilla y Vincennes, al armamento más moderno": Ph. PLAGNIEUX, "Les debuts de l'architecture flamboyante dans le milieu parisien", Les princes des fleurs de lis. La France et les arts en 1400, Paris, 2004, p. 86. El Religioso de SaintDenis habla del "gusto excesivo" de Carlos V por las fortificaciones.

17 J. CHAPELOT, "L'enceinte du château”, Les dossiers d'archéologie, 289 (2003-2004), pp. 104-115. Sobre los dispositivos defensivos en el piso alto de la torre: N. FAUCHERRE, op. cit., 1994, pp. 344-350.

18 J. CHAPELOT, op. cit., 2011, p. 158.

19 B. SCHIMMELPFENNIG, "Ad maiorem pape gloriam. La fonction des pièces dans le palais des Papes d'Avignon", Architecture et vie sociale. L'organisation intérieure des grandes demeures à la fin du Moyen Âge et à la Renaissance, Paris, 1994, p. 29.

20 S. GAIGNIÈRE, Le palais des papes d'Avignon, París, 1965, p. 10; B. SCHIMMELPFENNIG, op. cit., 1994, revisa el proceso constructivo y sobre todo el destino de los aposentos. Véase también nota 41. 
Berry enseñan que el esplendor arquitectónico de los Valois se forjó en el apego a fórmulas acastilladas ${ }^{21}$.

Era rasgo constitutivo de la arquitectura palaciega de la época la disposición en alto del espacio donde desarrollaban su vida reyes y nobles. La ampliación de Olite resulta ejemplar en este aspecto. La gran mayoría de piezas con elementos de confort, chimeneas y miradores, están situadas en el piso noble y todas las torres y galerías tienen un acceso principal a dicho nivel. La preferencia por la vida en alto igualmente cuenta con un claro antecedente en Vincennes, donde la llegada al trono de Carlos V supuso un cambio importante al respecto, puesto que la entrada de tiempos de Juan II fue abandonado en provecho de un ingreso directo desde el primer piso $^{22}$.
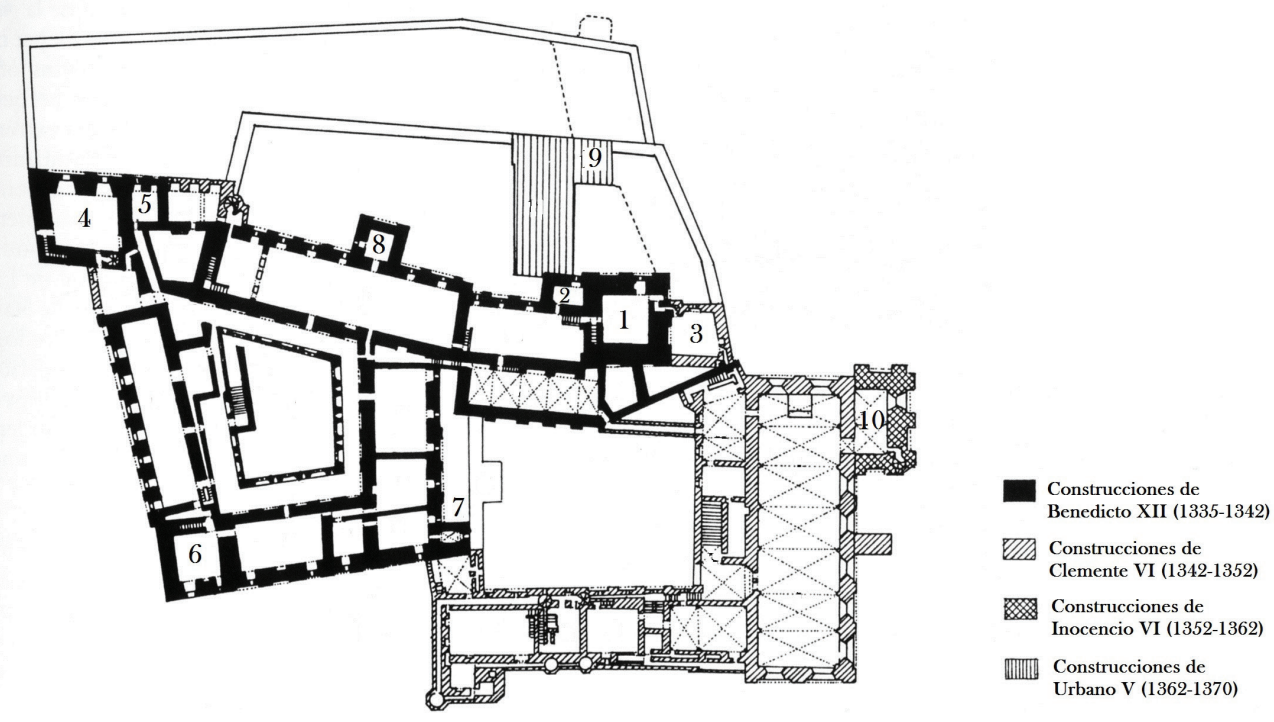

Fig. 2. Planta del Palacio de Aviñón (según Mesqui, 1993) con indicación de torres: 1. Torre del Papa. 2. Torre del Estudio (a su lado, letrina). 3. Torre del Guardarropa o de la Camera Cervi. 4. Torre de Trouillas. 5. Torre de letrinas. 6. Torre de la Campana. 7. Torre del Cardenal Blanco. 8. Torre de las Capillas. 9. Torre del Jardín. 10. Torre de San Lorenzo.

Resulta más llamativa, con relación al panorama parisino de 1400, la dinámica olitense consistente en la adición de torres que forman un núcleo irregular, asomado a jardines rodeados por galerías de trazado quebrado. Se aparta tanto del diseño

21 F. MICHAUD-FRÉJAVILLE, "Château et pouvoir dans les Très Riches Heures du duc de Berry", Château et pouvoir: Xe-XIXe siècles, Bordeaux, 1996, pp. 77-89. Es fundamental sobre la introducción de elementos residenciales en los castillos medievales J. MESQUI, Châteaux et enceintes de la France médiévale. De la défense à la résidence, Paris, 1993.

22 M. WHITELEY, "La Grosse Tour du Bois de Vincennes rencontre de la résidence et de la défense", Bulletin Monumental, 152 (1994b), p. 317, N. FAUCHERRE, op. cit., 1994. 
alrededor de una gran torre exenta (Vincennes), como de la organización en alas en torno a un patio, frecuentes ambas en el ámbito principesco ${ }^{23}$. Aunque parece haber primado el imperativo de aprovechar solares adquiridos a un lado y otro del cerco de la villa, no nos extrañaría que la acumulación de torres a manera de macla hubiera estado inspirada en el núcleo residencial del palacio aviñonés en torno a la gran torre del papa (fig. 2), obra de Benedicto XII, a la que anexaron las torres del estudio y de la camera cervi ${ }^{24}$.

Las cuentas de Olite anotan el trabajo de los artífices sucesivamente en distintas torres. De los encuentros entre muros se deduce que solían esperar a tener muy avanzada una unidad torreada antes de emprender la siguiente. Primero alzaron la Gran Torre sobre planta trapezoidal (el apéndice de su ángulo septentrional aprovecha un antiguo cubo de muralla). Cabe especular acerca de si la irregularidad de su planta estuvo condicionada por la adaptación parcial a otro edificio preexistente. Antes de terminarla emprendieron de una vez las torres de la Vit (de vis: escalera de caracol) y Nueva. El muro septentrional de la Vit se entrega, sin trabar la fábrica, al lienzo preexistente de la Gran Torre, mientras que el meridional está encadenado con la Torre Nueva. La galería con delicados arcos de piedra sobre el jardín se construyó prolongando los muros de la Gran Torre y de la Torre Nueva. La cámara rectangular aneja, identificada por Iriarte con el retrait dorado $^{25}$, se extiende entre la misma prolongación y una extensión paralela del muro meridional de la Torre Nueva.

Gran Torre y Torre Nueva contienen las principales estancias, amplias pero no pensadas para recepciones numerosas, dado que ya existían en el Palacio Viejo salas a tal fin (ése sería era el destino de la Cámara Luenga, al otro lado de la fachada principal). Carlos III dimensionó la ampliación pensando en aposentos para grupos reducidos, básicamente el soberano, su círculo íntimo y las visitas de calidad. Ha quedado completamente superado el antiguo y elemental esquema gran sala + cámara + capilla, sustituido por una variante de la suite residencial, en la que una cámara de parament (el término, documentado en Olite, se empleaba tanto en las residencias regias francesas como en Aviñón) funcionaba como aposento de representación y recepción, mientras que los retraits constituían ámbitos más reservados. La contigüidad de espacios con plantas y usos diferentes, inteligentemente comunicados, constituye un logro de la arquitectura bajomedieval, adaptable tanto a formatos longitudinales (donde frecuentemente fue preciso incluir una galería de paso) como a un donjon (que por su propia naturaleza era menos flexible desde el punto de vista de las comunicaciones, con lo que el paso por la sala central solía ser obligado).

En Vincennes la ornamentación, la distribución y las soluciones de circulación puestas en parangón con la información documental (inventarios) hacen factible reconstruir los cambios de uso de las salas y de los habitáculos alojados en las torrecillas de esquina ${ }^{26}$. En la planta noble (fig. 3) el pasillo intramural de la cara oriental, unido a la doble escalera del ángulo SO, facilitaba el acceso de los clérigos a la ca-

23 M. WHITELEY, op. cit., 1994b, p. 313.

24 O del Guardarropa: S. GAIGNIËRE, op. cit., 1965; y B. SCHIMMELPFENNIG, op. cit., 1994.

25 A. IRIARTE, op. cit., 1996, p. 338 y op. cit., 1998, p. 15.

26 M. WHITELEY, op. cit., 1994b. 


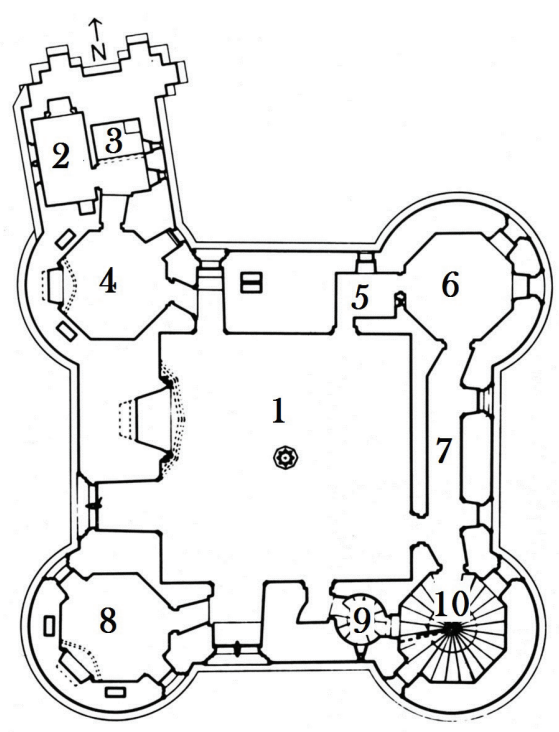

Fig. 3. Planta del piso noble del donjon de Vincennes (planta según Chapelot, 1994): 1. Sala del Rey. 2. Estudio. 3 Letrina. 4. Sala del tesoro. 5. Oratorio. 6. Capilla. 7. Pasillo de acceso a la capilla. 8. Retrait o guardarropa. 9. Escalera de servicio de todo el torreón. 10. Escalera principal.

pilla sin necesidad de atravesar la sala central del aposento regio. Por su parte, el rey podía asistir a la celebración ubicado físicamente en el espacio de la capilla, o bien seguirla a través de una ventana desde un pequeño oratorio intramural. El castillo de Saumur, construido entre 1367 y 1376 por orden de Luis de Anjou, proporciona un relevante ejemplo de composición en ala longitudinal con galería de comunicación ${ }^{27}$.

El núcleo maclado de la ampliación olitense combina de manera muy original rasgos de las distribuciones en torre y en alas. La adecuada jerarquización en la accesibilidad al monarca se obtuvo mediante un muy cuidado cálculo de la circulación, exclusiva de la planta noble, que interconecta cinco estancias y la galería (fig. 4):

1. La sala de la Torre Nueva pudo haber funcionado como cámara de parament, "principal pieza de recepción, donde eran recibidos los visitantes y donde se trataban los asuntos de estado" 28 . Recibía a través de una puerta apuntada a quien llegaba por la escalera de la Vit. Tiene puertas en sus cuatro lados. Las del muro norte, juntas y adinteladas, comunicaban con la Gran Torre y, a través de un pasillo intramural, con la galería sobre el jardín. La occidental, en arco apuntado, daba al retrait rectangular del rey y, gracias a un quiebro, también a la galería. La

27 M. WHITELEY, “'La Grande Vis'. Its development in France from the mid fourteenth to the mid fifteenth centuries", en L'escalier dans l'architecture de la Renaissance, París, 1985, pp. 16-17 y fig. 13.

28 M. WHITELEY, op. cit., 1994b, p. 323. 


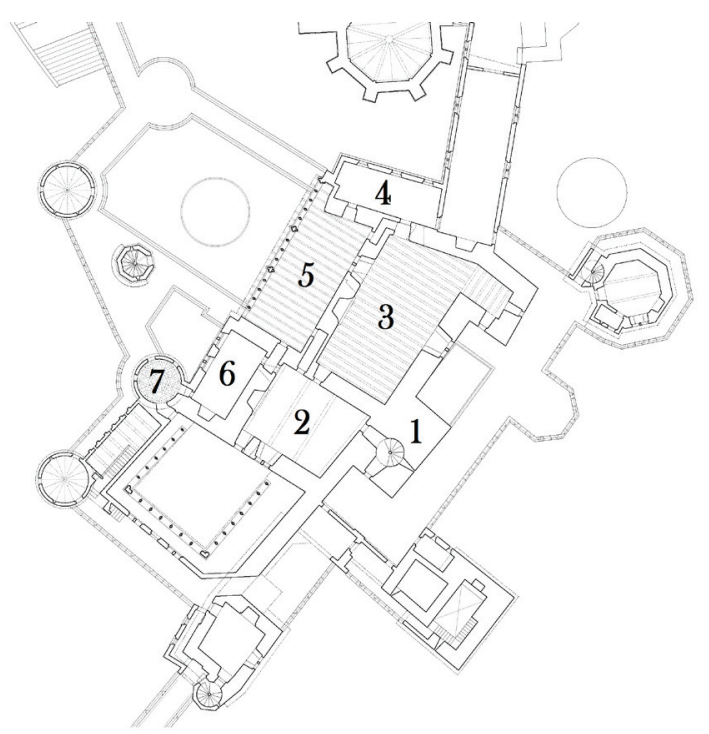

Fig. 4. Palacio de Olite. Planta del núcleo de la ampliación de Carlos III: Torre de la Vit. 2. Torre Nueva. 3. Gran Torre. 4. "Sala de los yesos". 5. Galería sobre el jardín. 6. Retrait dorado. 7. Cámara circular.

meridional, de medio punto, lleva hoy al jardín alto y en origen probablemente a otra galería.

2. La sala de la Gran Torre sería la pieza principal de residencia del rey. Con cuatro accesos, comunicaba por el Sur con la Torre Nueva; por el Norte con la llamada "sala de los yesos" (espacio cuyas dimensiones y trazado son conjeturales dado que llegó casi completamente perdido al siglo XX) y a través de otro pasaje intramural con la galería sobre el jardín; y por el Este con las torres exteriores.

3. La puerta oriental del retrait daba al pasillo intramural conducente a la Torre Nueva y a la galería sobre el jardín. La del ángulo opuesto llevaba a una cámara circular. La combinación de cámara reservada rectangular seguida de cámara circular guarda paralelismo asimétrico con los aposentos del ángulo noroeste del piso noble de Vincennes ${ }^{29}$, donde una estancia octogonal conecta con un reducido habitáculo rectangular (estudio del rey).

4. La cámara circular, restaurada como una de las garitas de esquina del muro perimetral, se diferencia de éstas en que asoma al jardín interior. Además de la puerta hacia el retrait, cuenta con otra hacia el claustrillo, que en principio comunicaría con una galería paralela al retrait y la Torre Nueva. Su tercer acceso, hacia las galerías perimetrales, es fruto de la restauración.

29 Según Whiteley, el retrait o guardarropa octogonal daba paso al estudio del rey: M. WHITELEY, "Les pièces privées de l'appartement du roi au château de Vincennes”, Bulletin Monumental, 148 (1990), pp. 83-85. Según Chapelot el espacio octogonal era la "sala del tesoro": J. CHAPELOT, op. cit., 2011, p. 163. 
5. La galería sobre el jardín conecta directamente con las salas de la Gran Torre y Torre Nueva, con el retrait y con la "sala de los yesos". Se diferencia en forma y dimensiones de las grandes galerías francesas nacidas a finales del siglo XIV cuya trayectoria estudió J. Guillaume ${ }^{30}$, así como de las restantes de Olite.

En resumen, gracias a la multiplicación de puertas y pasillos, desde cada pieza se podía llegar a las restantes mediante comunicación directa o a través de la galería. Era posible aislar cualquier habitación sin interrumpir las conexiones del resto del palacio. No dejan de sorprender sus similitudes con el esquema de distribución de estancias tras la remodelación del Louvre por Carlos V propuesto por Whiteley ${ }^{31}$.

Louvre: Cámara del rey ${ }^{32} \leftarrow$ cámara de retrait $\leftarrow$ cámara à parer $\rightarrow$ sala $\rightarrow$ dos habitaciones

Gran escalera

Olite: $\quad$ Galería sobre el jardín------------------Galería sobre el jardín

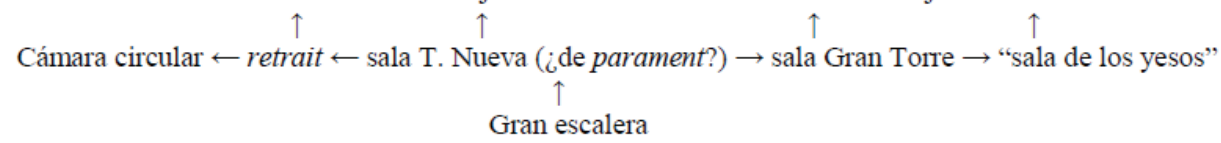

Carlos III y su arquitecto no pretendieron copiar una solución concreta, sino adaptar la circulación compleja de los palacios franceses a las posibilidades espaciales y a la dinámica de construcción de Olite.

Hemos conservado un único ingreso al piso noble del núcleo torreado que con certeza corresponde a la primera fase de obras: la escalera de la Torre de la Vit, adosada por su lado oriental a la Gran Torre y a la Torre Nueva ${ }^{33}$. La Vit (fig. 5) es un prisma de impactante volumetría. El énfasis en su masa la distingue de las restantes escaleras de caracol medievales de Navarra. Las hay de cierta amplitud, como las de La Oliva, Santa María de Tudela y Catedral de Pamplona. Pero la de Olite alcanza un grado de monumentalidad tan superior que los restauradores decidieron erróneamente elevar su culminación muy por encima de la terraza y rematarla en garitas, con el resultado

30 Sus dimensiones y exorno prueban que no es una mera galería de paso, pero carece de chimenea, "indispensable a toda galería-habitación": J. GUILLAUME, "Un tournant dans 1'histoire de la galerie: les hôtels parisiens de la fin du XIVe siècle”, Bulletin Monumental, 166 (2008), pp. 27-31. El clima y las tradiciones locales debieron de ser determinantes. Sobre otras galerías del palacio: A. IRIARTE, op. cit., 1998.

31 M. WHITELEY, op. cit., 1994a, p. 49.

32 A. SALAMAGNE, op. cit., 2009, fig. 5, añade la capilla y oratorio entre el retrait y la cámara del rey.

33 Sus dimensiones y localización parecen pensadas en función de los vanos de las fachadas anejas: en planta baja, una puerta en el paño libre de la cara oriental de la Torre Nueva y, en el piso sobre la planta noble, sendas ventanas en la Torre Nueva y en la Gran Torre. Sucesivas ampliaciones incrementaron las posibilidades de circulación. La Torre del Portal del Fenero contó con escalera de caracol desde el nivel de calle hasta la planta noble. El pasillo que partió en dos el jardín occidental termina en escalera que facilita el acceso a las galerías; este pasillo-galería no existía en el primer diseño del jardín. 


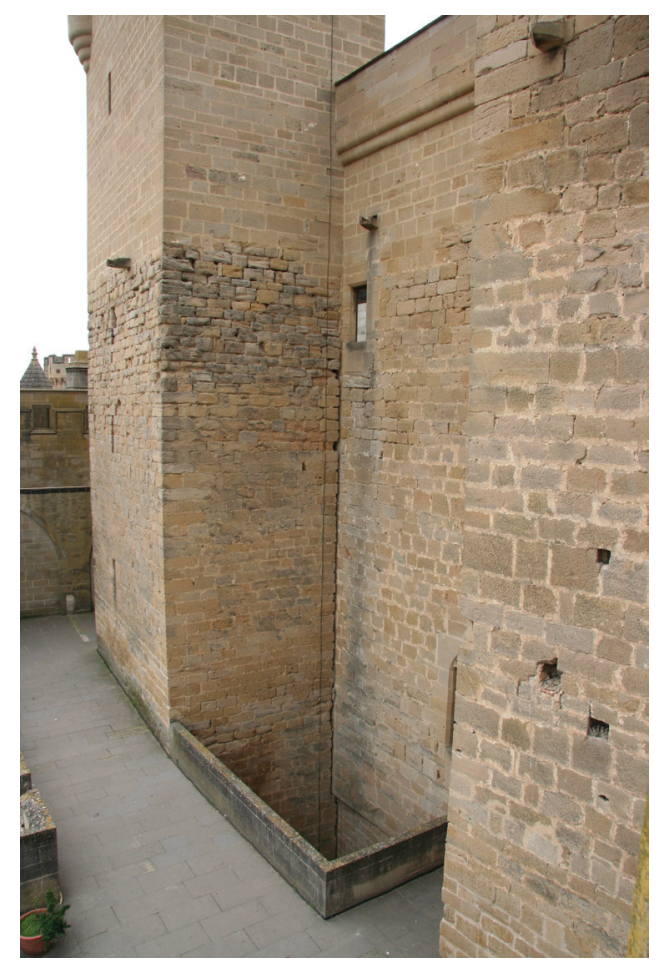

Fig. 5. Palacio de Olite. Torre de la Vit aneja a la Gran Torre.

de dotar al palacio de un equivalente miniaturizado de las torres del homenaje de los castillos castellanos del XV.

¿Por qué tales dimensiones para una simple escalera? Probablemente fue la versión simplificada que el arquitecto local realizó tomando como referente las grandes escaleras palaciegas francesas de la segunda mitad del siglo XIV, como la Grande Viz neuve del Louvre edificada en 1364 por Raymond du Temple, que algunos consideran "la escalera más famosa construida durante la Edad Media" ${ }^{34}$. Su destrucción hacia 1624 hace dudosa su traza. Según Whiteley tanto la caja como el interior eran cuadrados, con caracol de núcleo macizo. La autora argumenta que otros nueve edificios construidos para el rey de Francia o sus familiares directos entre finales del siglo XIV y mediados del XV coincidieron a la hora de recurrir a cajas cuadradas para escaleras principales: "parecería que esta forma se convirtió en un tipo reconocible de escalera real" ${ }^{35}$. La función de la Vit aunaría lo práctico y lo ceremonial, como la Grande Vis del Louvre. Según Plagnieux, "la entrada de honor se hacía directamente por la chambre à parer por medio de un nuevo tipo de escalera monumental, la grande vis: una

34 M. WHITELEY, op. cit., 1985, p. 15.

35 M. WHITELEY, op. cit., 1985, p. 16. 
escalera de caracol alrededor de un núcleo situada en una torre fuera de obra" ${ }^{36}$. Así lo habría entendido Carlos III, quien habría ordenado a Martín Périz que se atuviera a pautas portadoras de significado. En un artículo reciente, Salamagne sostiene que la del Louvre en origen fue hexagonal ${ }^{37}$; en tal caso, en Olite tendríamos una simplificación de la traza, en la línea de otras soluciones de la primera fase de obras.

A diferencia de Saumur o el propio Louvre, la gran escalera de Olite está emplazada detrás de las construcciones, no en su camino de acceso natural. Los imperativos de la circulación ya explicados y el deseo de dejar el mayor espacio posible al jardín en las caras meridional y occidental del complejo torreado son motivos suficientes para esta decisión. La ubicación en el centro de la fachada común de la Gran Torre y la Torre del Rey es comparable a la vis del palacio ducal de Bourges, que conoció personalmente Carlos III ${ }^{38}$. La destrucción del remate de la Vit impide saber si, como en el Louvre y en la Torre de Juan sin Miedo en París, la decoración se concentró en la bóveda ${ }^{39}$.

El terreno situado delante de las torres y la galería, en las fachadas más soleadas (meridional y occidental), fue dedicado a jardín. Lo protegió un muro de traza quebrada con garitas en las esquinas. Su superficie ocupaba una extensión inferior a la del complejo torreado. La inclusión de un jardín cerrado formaba parte de la tradición palaciega y su importancia se venía incrementando en estos años finales del siglo XIV. El Louvre y Vincennes contaban con jardines a los pies de los muros. Carlos III siguió comprando huertos para configurar uno mucho mayor entre el palacio y el río.

Nunca hubo un proyecto inicial, completo y cerrado que integrara la totalidad del Palacio de Olite tal y como quedó en 1425. Ciertamente, el complicado sistema de accesos en el núcleo implica la existencia de un proyecto parcial edificado torre a torre. A partir de ahí el crecimiento dependió de la voluntad del rey, quien no tuvo reparo en anular dispositivos residenciales construidos pocos años antes. Por ejemplo, la cortina exterior de la fachada oriental, por delante de la Gran Torre, dejó sin uso y en penumbra un mirador de la planta baja. Esta dinámica de cambios sobre la marcha no es infrecuente en los grandes palacios medievales. Carlos V modificó sustancialmente los planes de su padre Juan II para Vincennes. Según Chapelot, se advierten hasta cuatro modificaciones sucesivas en las obras del donjon entre 1361 y $1380^{40}$. En Aviñón, las sucesivas intervenciones de Juan XII, Bendicto XII, Clemente VI e Inocencio VI alteraron tanto el palacio episcopal previo como las fábricas de sus antecesores, con el añadido de que en ocasiones también hubo cambios de planes en vida de un mismo papa ${ }^{41}$. En arquitectura, como en otras facetas de su existencia, la

$36 \mathrm{Ph}$. PLAGNIEUX, "La résidence parisienne de Jean sans Peur. Un palais pour la réforme du royaume", La Cour du Prince. Cour de France, cours d'Europe XIIe-XVe siècle, París, 2011, p. 133.

37 A. SALAMAGNE, op. cit., 2009, pp. 102-103, fig. 19.

38 M. WHITELEY, op. cit., 1994a, fig. 6.

39 Ph. PLAGNIEUX, op. cit., 2011, pp. 125-143 En la tradición navarra también existían bovedillas de esmerada arquitectura rematando escaleras de caracol, como la de la Capilla Barbazana en la catedral de Pamplona, de la primera mitad del siglo XIV, aunque carece de elementos figurativos.

40 J. CHAPELOT, op. cit., 1996; y op. cit., 2011, pp. 149-150.

41 F. PIOLA CASELLI, La costruzione del palazzo dei papi di Avignone (1316-1367), Milán, 1981, pp. 59-103;B. SCHIMMELPFENNIG, op. cit., 1994. 


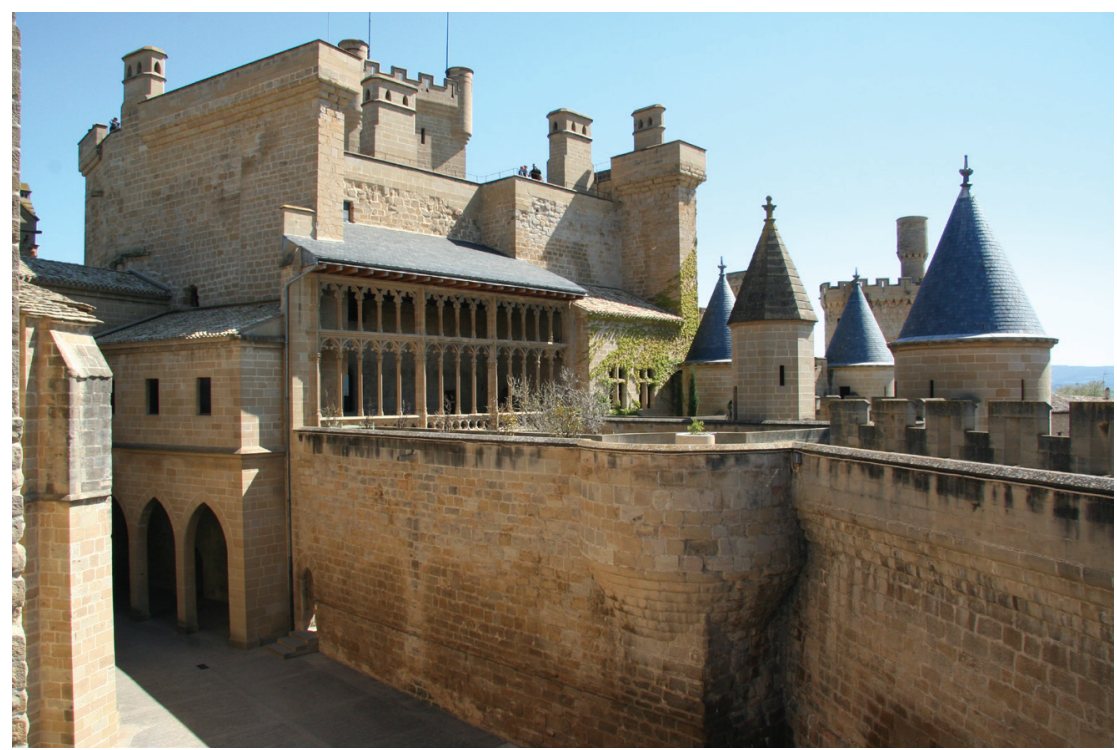

Fig. 6. Palacio de Olite. Al fondo, galería sobre el jardín por delante de la Gran Torre y de la Torre Nueva. En primer término a la derecha, galerías perimetrales del jardín.

satisfacción de caprichos personales fue una constante en la actuación de la realeza bajomedieval.

El refinamiento en la comunicación y la complejidad espacial olitenses no están acompañados por soluciones constructivas de vanguardia. Podría pensarse que en sus primeros encargos, Carlos III fue partidario de la austeridad arquitectónica de quien parece haber sido su modelo en este campo, Carlos V de Francia, o bien que hubo de contentarse con lo que le permitieron sus posibilidades económicas anteriores a la recuperación de las propiedades francesas. La ejecución del proyecto fue confiada al maestro de obras del rey, el navarro Martín Périz de Estella, quien empleó recursos propios de un artífice con oficio, posiblemente formado en la construcción y reparación de castillos y parroquias ${ }^{42}$. La solidez de la fábrica reside en el considerable grosor de los muros, capaces de contener en su interior pasillos, miradores, tiros de chimenea o las hojas de las puertas. Algunas de las soluciones más llamativas tienen antecedentes en edificios navarros frecuentados por los monarcas. Por ejemplo, garitas que jalonan las esquinas existían en el castillo de Tiebas ${ }^{43}$. La galería sobre el jardín (fig. 6) con su gran arco rebajado combina al menos dos precedentes: 1) los arcos de piedra en que apoyan ciertas tribunas occidentales en iglesias navarras de

42 Sobre Martín Périz de Estella; J. MARTÍNEZ DE AGUIRRE, op. cit., 1987, pp. 104-105; y "Martín Périz de Estella, maestro de obras gótico, receptor y promotor de encargos artísticos", VII CEHA Murcia, 1988: Mesa I Patronos, promotores, mecenas y clientes, Murcia, 1992, pp. 73-80.

43 Se ven en dibujos previos a la ruina: J.J. MARTINENA, Navarra castillos y palacios, Pamplona, 1980, p. 93. El sistema de soporte difiere. Las de Tiebas apoyaban en contrafuerte y dos ménsulas, mientras que las de Olite disponen (como en Vincennes) de anillos mensulares concéntricos continuos y decrecientes. 
los siglos XIII y XIV ${ }^{44}$; y 2) la galería de la fachada occidental sobre arcos de piedra de Santa María de Ujué, iglesia frecuentada por los Evreux, edificada en la primera mitad del siglo XIV ${ }^{45}$. Otros dispositivos parecen fruto del ingenio del maestro. La sala de la Torre Nueva, en la planta noble, es más ancha que la cámara abovedada que la soporta. Para asentar correctamente el muro desplazado, Martín Périz lanzó un arco por delante de la pared meridional en la planta baja de la Gran Torre. Otro arco en el muro oriental de la misma sala baja permitió regularizar el correspondiente de la planta noble (tomando la precaución de colocar el hueco del mirador sobre la parte central del arco).

La escultura ornamental se concentra en la galería sobre el jardín, las chimeneas, las ventanas y los miradores de la planta noble. Intervinieron artistas familiarizados con la hojarasca menuda y sinuosa de la época. La cuidada molduración de la tracería recuerda al claustro catedralicio pamplonés (cuya iglesia estaba en obras por esos mismos años). El esmero en este tipo de ornamentación fue una constante en los palacios de los Valois, como apreciamos en Mehun-sur-Yèvre, las escaleras de Lavardin y de la Torre de Juan Sin Miedo en París. No hay noticias de esculturas en nichos de fachada, como las hubo en Vincennes, La Ferté-Milon o Pierrefonds (el Museo de Navarra custodia dos esculturas descabezadas halladas durante las obras en el entorno del palacio).

No es el lugar para analizar los programas pictóricos, vidrieras y tapices, los muebles y complementos ornamentales que transfiguraban los interiores. Desde luego, el marco arquitectónico que nos ha llegado, caracterizado en la planta noble por la presencia de elementos de confort (chimeneas, miradores), unido a las noticias documentales, permitiría reproducir en los aposentos de Olite escenarios amueblados casi idénticos a los de las miniaturas que ilustran el modo de vida palatino de la época en Francia ${ }^{46}$. Tampoco puedo ocuparme aquí de los elementos pertenecientes a tradiciones hispanas (techumbres de lazo, paneles de yeso con lacerías y ataurique, pavimentos y paredes de azulejos, etc.) que hicieron del palacio una singular expresión de mestizaje.

44 No asienta sobre una bóveda, como era normal en las tribunas occidentales eclesiales (Artajona, Ujué, San Cernin de Pamplona, etc.), sino sobre un forjado sostenido por un gran arco de piedra frontal, como se había hecho en la iglesia de Legarda en Mendavia en el siglo XIII (J. MARTÍNEZ DE AGUIRRE y F. MENÉNDEZ PIDAL, Emblemas heráldicos en el arte medieval navarro, Pamplona, 1996, p. 199).

45 Sobre la galería ujuetarra: J. MARTÍNEZ DE AGUIRRE, “Arquitectura medieval”, Santa María de Ujué, Pamplona, 2011, pp. 92-96. Los muros que se prolongan a manera de antas hasta la arquería recuerdan a la disposición de balconadas mediante continuación de muros maestros, recurso habitual de los caseríos en comarcas montañosas del reino, cuyos ejemplos más antiguos no cabe fechar con certeza.

46 Me refiero a imágenes de interior como las de los Diálogos de Pierre Salmon (ejemplares de Ginebra, Biblioteca Pública y Universitaria, ms. fr. 165, fol. 4, y París, Biblioteca Nacional de Francia, Fr. 23279, fol. 53); o las Obras de Cristina de Pisan: Londres, British Library, Harley 4431, t. I, fol. 3. Vemos en Olite un rasgo particular: las salas de la Gran Torre y la Torre Nueva disponen de ventanas altas por encima de los miradores, probablemente pensadas para garantizar la iluminación natural cuando las contraventanas se cerraban a fin de que nadie pudiese ver desde el exterior lo que sucedía dentro. Sin embargo, conviene recordar que en Vincennes ya había aposentos exclusivamente iluminados mediante ventanas altas, que impedían la visión y el acceso al espacio de los reyes. Parecen allí dispuestas como medida de seguridad: M. WHITELEY, op. cit., 1994b, p. 317. También apreciamos ventanas altas suplementarias en el Grand Tinel de Avignon. 


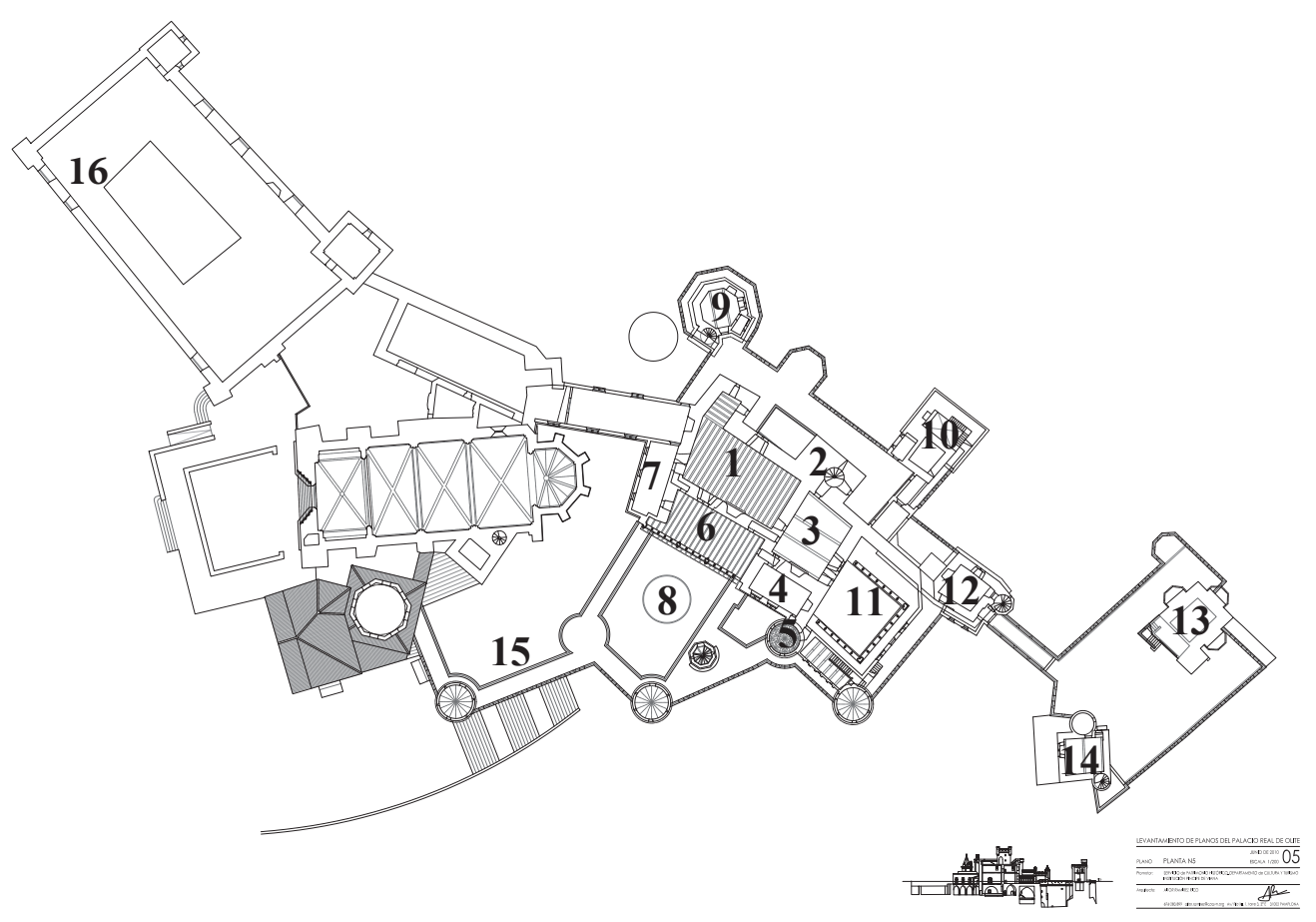

Fig. 7. Palacio de Olite. Planta del piso noble (Institución Príncipe de Viana): 1. Gran Torre. 2. Torre de la Vit. 3. Torre Nueva. 4. Retrait dorado. 5. Cámara circular. 6. Galería sobre el jardín. 7. "Sala de los yesos". 8. Jardín. 9. Torre Ochavada. 10. Torre del Aljibe. 11. Claustri1lo. 12. Torre del Portal del Fenero. 13. Torre de las Tres Grandes Finiestras. 14. Torre de la Joyosa Guarda. 15. Muro perimetral añadido. 16. Cámara Luenga en el Palacio Viejo.

\section{Las ampliaciones a partir de 1411: imaginario y literatura}

Carlos III regresó de su tercer viaje a Francia en enero de 1411. La intervención de un nuevo equipo especializado en el trabajo de la piedra a partir de esa fecha supuso un cambio cualitativo en sus empresas arquitectónicas y escultóricas. Lo encabezaba Johan Lome de Tournai ${ }^{47}$, quien recibió el encargo del sepulcro regio para la catedral de Pamplona. Muy probablemente el rey lo había conocido durante su estancia en Dijon durante el mes de noviembre de 1410. Se le supone colaborador del taller de Claus de Werve al servicio del duque de Borgoña.

47 Sobre Johan Lome sigue siendo fundamental R.S. JANKE, Jehan Lome y la escultura gótica posterior en Navarra, Pamplona, 1977. Ha avanzado en la caracterización estilística de su obra C. FERNÁNDEZLADREDA AGUADÉ, "La escultura en Navarra en la primera mitad del siglo XV. Johan Lome y su círculo", Anales de Historia del Arte, extra 2012, pp. 7-37. Sobre su participación en los encargos de la reina Blanca: J. MARTÍNEZ DE AGUIRRE ALDAZ, "El honor de la Corona: las empresas artísticas de la reina Blanca de Navarra (1425-1441)", Goya: Revista de arte, 334 (2011), pp. 40-57. 


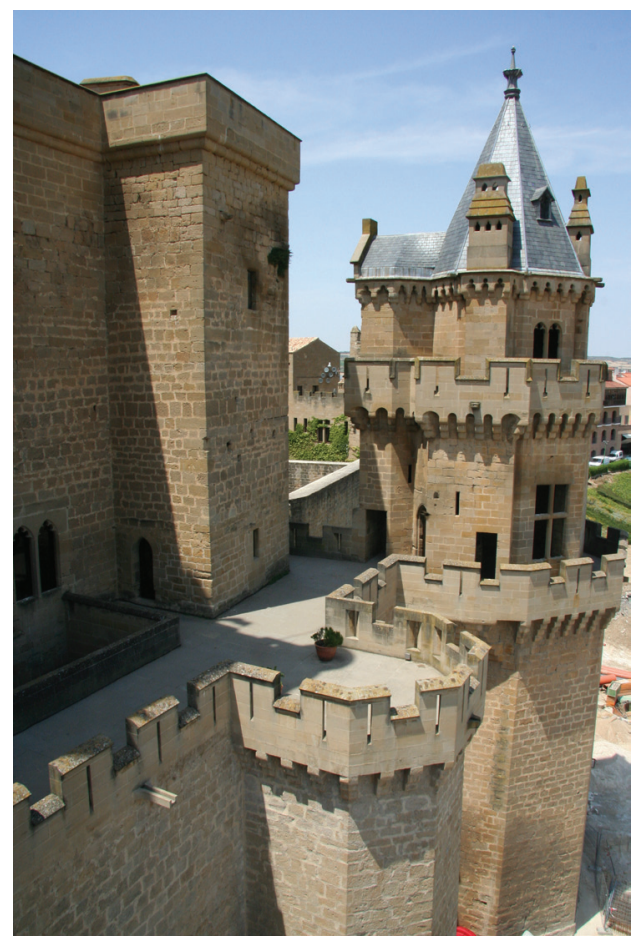

Fig. 8. Palacio de Olite. Torre Ochavada; a la izquierda, Gran Torre.

Los cambios de planes fueron frecuentes en los encargos palaciegos de los monarcas de la época, pero desconozco otro caso en que se produjera un giro tan singular en la dinámica creativa. De un palacio pensado para la generación de espacios propios de la realeza basados en la sabia ordenación de un núcleo compacto, combinando la distribución útil y el lujo asequible, pasamos a la proliferación de unidades dispersas que añadieron ámbitos refinados, caprichosos e inesperados (fig. 7) . No es fácil adivinar las motivaciones de estas edificaciones, que parecen explorar los efectos de la sorpresa y la imaginación. Ni reconocemos la introducción de aposentos "a la francesa" o "a la castellana", ni responden a demandas utilitarias. Ahora bien, más allá del capricho tuvo que haber una intención.

Nos centraremos en las nuevas torres. Entre 1412 y 1413 los maestros trabajaron en la Ochavada (fig. 8), construcción cercana y comunicada pero independiente del núcleo torreado. Tenía dos niveles, con sendas chimeneas. En la planta noble, la estancia octogonal y el diminuto aposento rectangular dispuesto en su cara meridional nos recuerdan a las torrecillas de esquina de Vincennes. El francés Johan Lescuyer añadió un rico complemento de carpintería que acentuaba las semejanzas con 


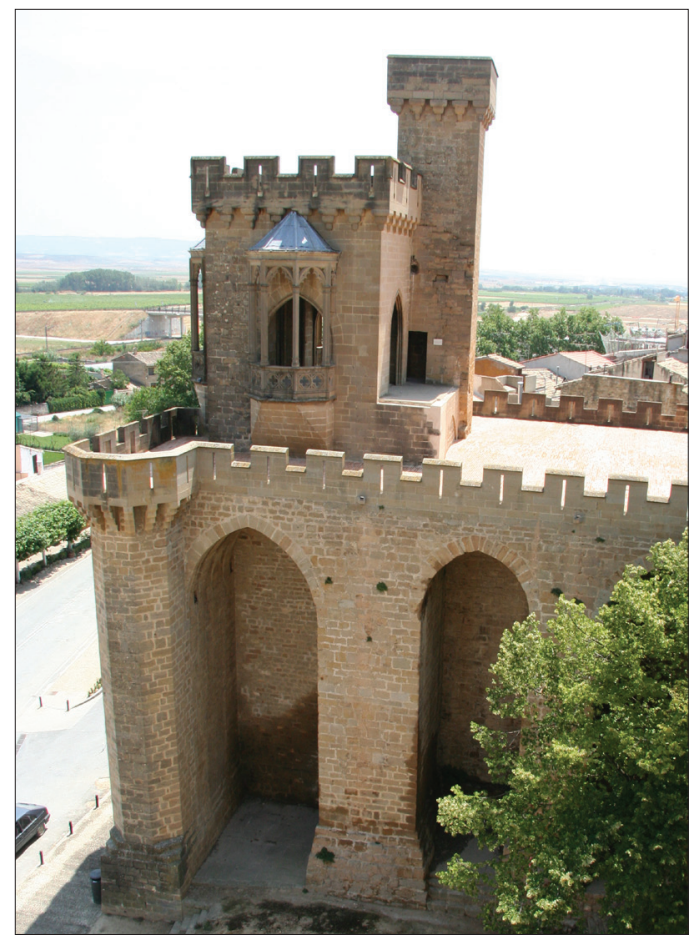

Fig. 9. Palacio de Olite. Torre de las Tres Grandes Finiestras.

el torreón cercano a París, donde "todas las salas que constituían la vivienda del rey estaban revestidas de madera" ${ }^{48}$. ¿Fue un nuevo retrait más exquisito, concebido a manera de cita arquitectónica metonímica -la parte por el todo- del gran donjon de Carlos V?

En verano de 1413 comenzaron a asentar la Torre del Portal del Fenero, que facilitó la extensión del palacio al otro lado de la puerta de la población. En el extremo alejado del núcleo torreado, al que se accedía por una estrecha galería, construyeron en 1414 la Torre de las Tres Grandes Finiestras y la Torre de la Joyosa Guarda. En 1418-1419 le llegó el turno a la "calostra del rey (...) de çaga la cambra de los ángeles", identificable con el claustrillo al Sur de la Torre Nueva.

Las formas de estos últimos encargos llevan al límite el capricho y la invención. La Torre de las Tres Grandes Finiestras (fig. 9) contenía una reducida estancia con planta de cruz griega abierta a tres ventanales. Aunque la forma externa de los miradores es producto de la restauración, inspirada en la desaparecida Torre de Ochagavía del Palacio de Tafalla, las fotografías previas muestran que los tres vanos estaban allí. Por tanto, estamos ante un espacio que no parece haber cumplido otra función que la de

48 J. CHAPELOT, op. cit., 2011, pp. 160-165. 


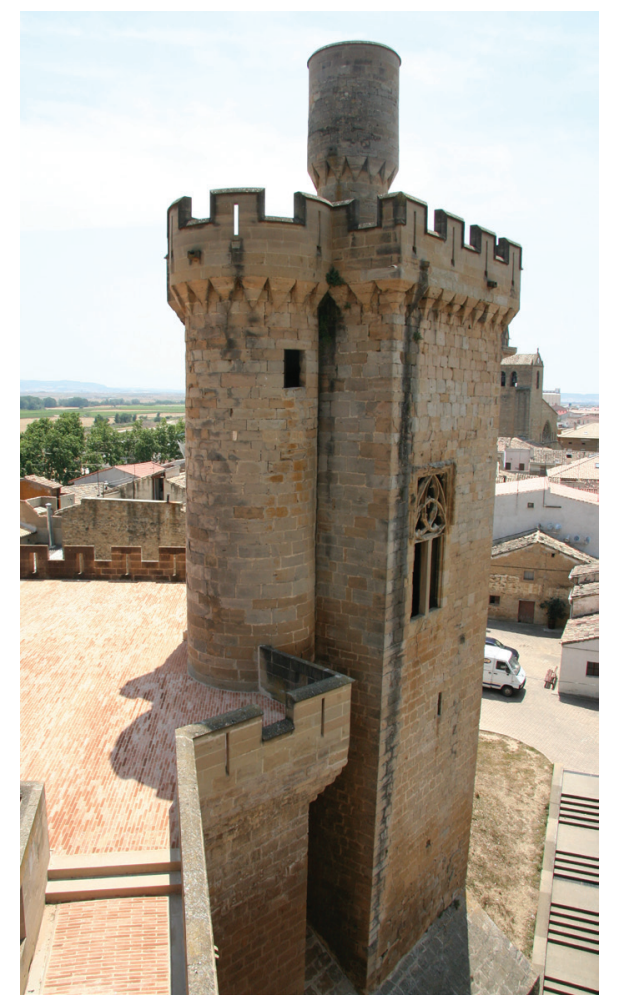

Fig. 10. Palacio de Olite. Torre de la Joyosa Guarda.

ser un Bel Regart, como el de Tudela. Serviría para contemplar los jardines, la vega del Cidacos, el lejano santuario de Ujué recortado sobre la sierra o los festejos que podrían tener lugar a los pies del palacio. Ya Meyer Schapiro llamó la atención sobre un pasaje de la historia de los abades de Saint-Trond que pone en claro la importancia de los "ventanales amplios y ligeros que proporcionaban un vasto panorama desde el interior de la casa y ofrecían a los ojos del contemplador una vista completa de casi media ciudad" en la arquitectura residencial desde época románica ${ }^{49}$. La acción de contemplar algo (justas, posesiones, etc.) desde lo alto del castillo constituía una ocupación recurrente de los reyes y la corte en la literatura bajomedieval.

La Joyosa Guarda presenta igualmente una distribución peculiar (fig. 10). Cada una de sus dos plantas consta de dos estancias separadas por puertas. Una tiene planta rectangular y la otra circular. Vienen a ser la quintaesencia de un retrait: un lugar apartado, en el extremo del palacio, que a su vez da paso a otro todavía más recóndito. La tracería de la ventana de la planta noble reproduce uno de los emblemas para-

49 M. SCHAPIRO, "Sobre la actitud estética en el arte románico (1947)”, Estudios sobre el románico, Madrid, 1984, p. 26. 


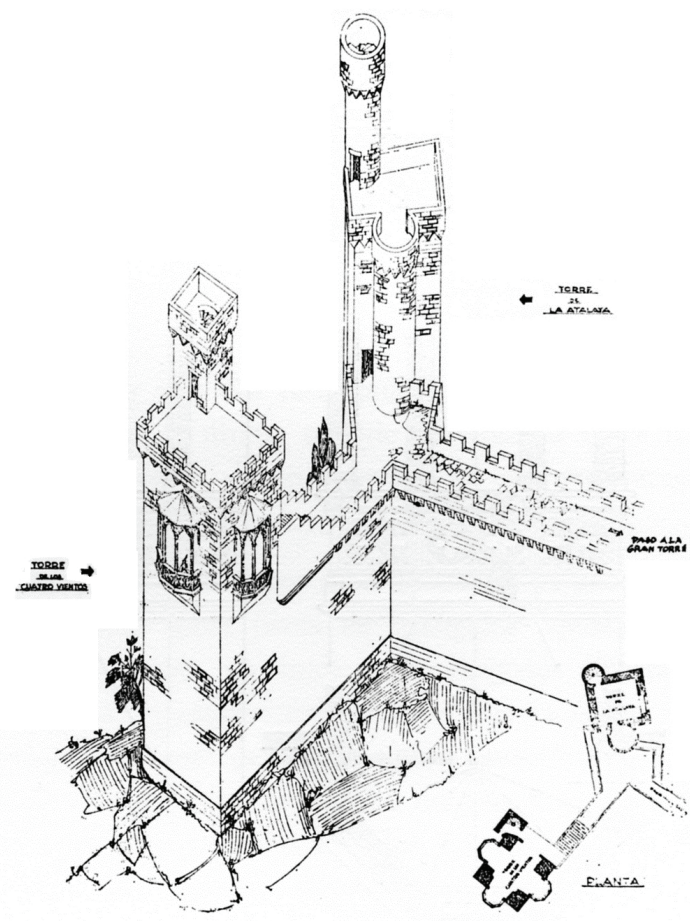

Fig. 11. Palacio de Olite. Torres de la Joyosa Guarda y de las Tres Grandes Finiestras en su disposición original, según Yárnoz.

heráldicos del monarca: el lazo de triple ojiva que empleaba en su signeto ${ }^{50}$. Culmina la torre una llamativa atalaya circular, de esbeltísimas proporciones. Paradójicamente esta torrecilla de vigía está colocada hacia el interior de la localidad, es decir, hacia donde su presumible función sería menos necesaria.

Las Tres Grandes Finiestras y la Joyosa Guarda comparten hoy una amplia terraza, pero -como vio Yárnoz- la disposición original había sido muy diferente ${ }^{51}$ (fig.11). La estrecha galería que partía de la Torre del Portal del Fenero se bifurcaba para terminar en sus respectivos ingresos. Eran dos aposentos apartados, remotos en lo espacial y en lo formal. Más que en ningún otro ámbito del palacio, allí podría retirarse el monarca para recrearse en sus actividades, pensamientos o ensoñaciones.

El claustrillo, por sí mismo, quizá no llame demasiado nuestra atención en la actualidad, puesto que en su casi totalidad es fruto de la restauración. En su tiempo

\footnotetext{
50 F. MENÉNDEZ PIDAL, M. RAMOS AGUIRRE y E. OCHOA DE OLZA EGUIRAUN, Sellos medievales de Navarra. Estudio y corpus descriptivo, Pamplona, 1995, 1/92, p. 140. También adorna una bóveda de la catedral de Pamplona con las armas de su hija Blanca: M. RAMOS AGUIRRE, "Decoración emblemática", La catedral de Pamplona, Pamplona, 1994, I, p. 387.

51 J.J. YÁRNOZ, op. cit., 1941
} 


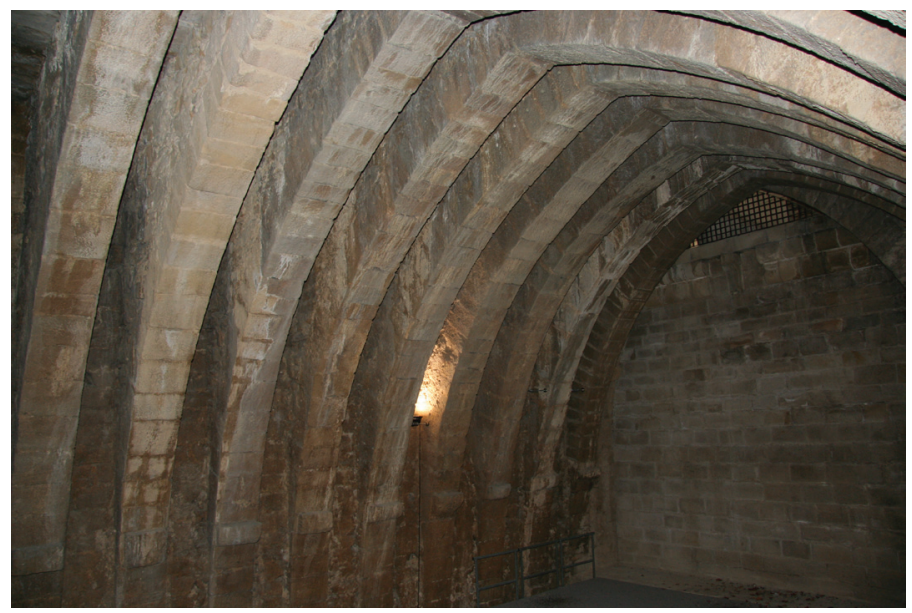

Fig. 12. Palacio de Olite. Arcos que soportan el claustrillo.

debió de resultar muy sorprendente encontrar un jardín tan elevado con respecto al nivel del suelo del inmediato Portal del Fenero. Es aconsejable volver al interior del palacio para experimentar el impacto visual provocado por la contemplación de la poderosa estructura que lo sostiene (fig. 12). Diez enormes arcos de piedra soportan el enlosado de piedra bajo la tierra del vergel. La pieza en permanente oscuridad fue bautizada por los lugareños como Sala de los Murciélagos.

A mi juicio la clave para entender esta fase del palacio podría encontrarse en la denominación de la Torre de la Joyosa Guarda. Todo lector de literatura artúrica sabe que Joyosa Guarda o Guardia Alegre es el nombre que recibió el castillo de la Guardia Dolorosa (así conocido porque "todos los caballeros andantes que llegaban, allí morían o eran hechos prisioneros" ${ }^{52}$ ) una vez que Lanzarote consiguió vencer a los sucesivos contingentes de defensores con ayuda de los escudos de propiedades maravillosas que le aportó la doncella ${ }^{53}$ (escudos decorados con el que en adelante sería su emblema heráldico: bandas de gules en campo de plata). Esta aventura constituye uno de los episodios nucleares del Lanzarote del Lago (Lancelot du Lac en prose).

Sin duda fue el propio monarca quien dio nombre a la torre. Es tentador imaginar a don Carlos descubriendo en las páginas del Lanzarote la inspiración para la ampliación final de su palacio preferido. No podía mimetizar el entorno del castillo tal y como lo describe el libro, porque la Guardia Dolorosa se alzaba sobre una enorme roca rodeada por dos ríos. Así la vio el Caballero Blanco en su primera aproximación:

"Contempló el castillo y lo ve altivo y hermoso, bien asentado, pues toda la fortaleza está sobre una alta roca escarpada, que no es nada pequeña, pues tiene de lado a lado

52 Historia de Lanzarote del Lago. 1. La Reina del Gran Sufrimiento, tr. C. Alvar, Madrid, 1995, p. 208.

53 Historia de Lanzarote del Lago, 1995, pp. 212-214. 
más de un tiro de ballesta. (...) Al pie de la roca, por un lado, corre el río Humber, y por el otro pasa un gran río que nace de más de cuarenta fuentes. (...) Había dos pares de murallas y en cada una había una puerta; en cada puerta tenía que combatir con diez caballeros. (...) Sobre la puerta de la otra muralla había un caballero de bronce, grande, corpulento, montado a caballo y armado completamente; sujetaba con las manos una enorme hacha y se mantenía en aquel lugar por un encantamiento. (...) Pasadas las murallas estaba el burgo, bien abastecido, en el que se podían encontrar todas las cosas necesarias a cualquier caballero andante." 54

La topografía de Olite hacía poco factible reproducir esta primera visión. El único rasgo coincidente era la continuidad entre fortaleza y burgo. Pero quizá otros pasajes estimularon metonímicamente la imaginación del soberano y su arquitecto a la hora de proyectar nuevas formas arquitectónicas. La Torre de la Joyosa Guarda es pequeña, lo que coincide con la descripción del "palacio del señor del castillo", al que fue conducido Lanzarote tras la conquista: "uno de los edificios más hermosos del mundo, aunque era pequeño" 55 . Su culminación en atalaya casa con las reiteradas menciones de la "atalaya de defensa de la Guardia Dolorosa" ${ }^{6}$. La atalaya es el elemento más llamativo de nuestra torre olitense, hasta el punto que como "Torre de los Atalayas" (sic) era conocida en el siglo XIX ${ }^{57}$. Otro pasaje describe al señor del castillo "sentado a la mesa en una alta torre, en uno de los extremos del palacio [donde] comía atendido por un gran número de servidores y con una vajilla riquísima" 58 . También en Olite esta alta torre se sitúa en el extremo del palacio.

Otros aposentos olitenses sufrieron transformaciones en la segunda fase de obras que los hicieron parecerse al castillo de la Guardia Dolorosa. Recordemos el fragmento del Lanzarote del Lago en que, tras encaminarse al cementerio, Galván y sus compañeros regresan "por delante de la puerta que estaba cerrada, pero encuentran abierto el jardín: entran en él y llegan ante la galería de una bellísima sala"59. La descripción trae a la memoria dos secuencias arquitectónicas del palacio navarro: a) la disposición del jardín en el actual patio de la morera que, una vez añadido el muro separador con su escalera, conducía a la galería sobre el jardín delante de la principal sala del rey; y b) la percepción que ofrece a quien viene desde la Torre de la Joyosa Guarda el jardín en alto con sus galerías a manera de claustro ante la sala de la Torre Nueva ${ }^{60}$.

54 Historia de Lanzarote del Lago, 1995, pp. 207-208.

55 Historia de Lanzarote del Lago, 1995, p. 221.

56 Historia de Lanzarote del Lago, 1995, pp. 224, 226; sobre guardianes en torres: pp. 246, 247

57 J. ITURRALDE Y SUIT, A. LAGARDE e I.J. URRICELQUI, op. cit., 2006, pp. 23 y 43.

58 Historia de Lanzarote del Lago, 1995, p. 232.

59 Historia de Lanzarote del Lago, 1995, p. 225.

60 En otros pasajes la comparación con Olite resulta más forzada. Por ejemplo, la división en dos espacios de la Joyosa Guarda podría relacionarse con las dos puertas de la Guardia Dolorosa, como narra el recorrido de Galván y otros caballeros cuando cabalgaron "hasta la atalaya; desde allí vieron que la primera puerta estaba abierta; entraron y se encontraron con la otra cerrada" (Historia de Lanzarote del Lago, 1995, p. 224). No quiero ocultar que entre las dos puertas de la Guardia Dolorosa había un patio, por lo que no existe un paralelismo riguroso. Más adelante dice el Lanzarote: "la reina entra en el castillo y sube a las murallas para ver desde allí los combates", (p. 261), fragmento que pudo inspirar la construcción de una torre destinada solamente a la contemplación, como las Tres Grandes Finiestras, aunque ya hemos dicho que la acción 
Dentro de esta última fase de obras, el rey Noble mandó ampliar el recinto amurallado con un nuevo muro que conectaba, siguiendo un trazado en ángulo recto, el antiguo cierre trapezoidal del jardín con la iglesia de Santa María. Además dividió el antiguo jardín en dos, también con un pasillo intramural y escalera. Quedaba así configurada una sucesión de murallas y puertas que podría rememorar las disposiciones del ingreso de la Guardia Dolorosa, donde Lanzarote combatió con los defensores.

No creo que estemos una serie azarosa de rebuscadas coincidencias, sobre todo porque el único capaz de poner un nombre tan elocuente a la Torre de la Joyosa Guarda era el propio rey. Hasta donde sabemos, nadie más con la formación literaria necesaria tuvo responsabilidad directa en la construcción del palacio. Las restantes torres recibieron denominaciones descriptivas de su forma o función.

Como sucedió en Francia, la moda de los nombres artúricos se constata en la documentación navarra en la segunda mitad del siglo XIV ${ }^{61}$. La afición a la Materia de Bretaña le llegaría a Carlos III a través de su familia francesa. Los estudios de M.P. Lafitte y M.H. Tesnière prueban que el gusto de Carlos V, sus hermanos y su hijo por este tipo de literatura quedó reflejado en los inventarios y manuscritos conservados ${ }^{62}$. También los afectos literarios del soberano navarro se dejaron seducir por la figura de Lanzarote, hasta el punto de poner los medios para que su hermano bastardo Leonel aprendiera a leer con el relato de sus aventuras. En 1392 ordenó pagar 10 sueldos al rabí de los judíos de Tudela por encuadernar el romance de Lancelot "emprestado a mosén Laoniel por aprender a leir" ${ }^{63}$. La inclinación se manifiesta en aspectos más personales. Carlos III tuvo fuera del matrimonio dos hijos que recibieron los nombres de Lancelot y Godofre. Proyectó en ellos sus propios ideales: por una parte, el más esforzado paladín de la Tabla Redonda; por otra, el cruzado Godofredo, conquistador y rey de Jerusalén. Ambos integraban el grupo de los Nueve Héroes o Barones (Neuf Preux) citados por Jacques de Longuyon en los famosos Voeux du Paon. Junto

de contemplar aparece en muchas otras obras literarias de la época. Finalmente, el efecto de conjunto que producía el Palacio de Olite con su multiplicación de galerías visto desde el interior de la población sería semejante al del "hermoso castillo" de la Guardia Dolorosa, donde "todas las casas tenían galerías por la parte delantera, abajo o arriba" (pp. 244-245).

61 En el último tercio del siglo la sitúa M. PASTOUREAU, "La réception de la légende arthurienne (XIIIe-XIVe siècle)", La légende du roi Arthur, Paris, 2009, p. 37. En Navarra identificamos un mensajero de Pamplona llamado Lancelot en 1361 y un forrajero del mismo nombre en 1395: Archivo General de Navarra, Comptos (AGNC), Caj. 14, $\mathrm{n}^{\circ}$ 145, 1 y Caj. 78, $\mathrm{n}^{\circ}$ 27, 8 (1). Carlos II tenía un sobrino de ese nombre en 1367: AGNC, Caj. 25, no 25, 3 (1). A comienzos del siglo XV conocemos un Lancelot hijo del médico del rey Juan Moliner, otro valet de cámara y un tercero hijo del mercader pamplonés Juan Ruiz: AGNC, Caj. 82, nº 9, 19; Caj. 83, no 6, 16; y Caj. 84, no 9, 45.

62 M.P. LAFITTE, "Les romans de la Table ronde dans les bibliothèques médiévales et leur sort jusqu'au XVIIIe siècle", La légende du roi Arthur, Paris, 2009, pp. 44-45; M.H. TESNIÈRE, "Les romans de la Table ronde dans la Librairie royale de Charles V et Charles VI", La légende du roi Arthur, Paris, 2009, p. 51 y 70-72. Igualmente Juan de Berry y Felipe el Atrevido poseían ejemplares, algunos muy suntuosos. Philippe de Mézières advirtió al joven Carlos VI de los peligros que comportaba su lectura, sin llegar a convencerle. Margarita de Baviera, esposa del duque de Borgoña Juan sin Miedo, tenía en su biblioteca tres ejemplares del Lancelot en prosa: D. JEANNOT, "Les Bibliothèques de princesses en France au temps de Charles VI: l'exemple de Marguerite de Bavière", Livres et lectures de femmes en Europe entre Moyen Âge et Renaissance, Turnhout, 2007, pp. 191-210.

${ }^{63}$ AGNC, Caj. 61, no 4, IV, citado por J. YANGUAS Y MIRANDA, Diccionario de Antigüedades del Reino de Navarra, Pamplona, 1964, t. II, p. 33. 
a Carlomagno eran los representantes de la tríada cristiana. De este modo, dicha tríada literaria quedó ligada en el linaje de nuestro soberano, puesto que el rey Noble consideraba a Carlomagno antepasado suyo, como proclama su epitafio ${ }^{64}$. El tema de los Nueve Héroes era de total actualidad entre los príncipes Valois, cuyos palacios incluyeron estatuas y tapicerías de los paladines. Luis de Orléans (hermano de Carlos VI) dispuso en las torres, cortinas y puertas de la fortaleza de Pierrefonds nichos para estatuas religiosas y profanas de unos dos metros de altura. Como era de esperar, los nueve héroes fueron destinados a las torres. Él mismo emprendió en 1398 la construcción del castillo de La Ferté-Milon, cuyas torres reservaron hornacinas para las Neuf Preuses ${ }^{65}$. En 1389 el tapicero Jacques Dourdin, que también fue proveedor de Carlos III, entregó un tapiz con los nueve héroes al duque de Borgoña, quien diez años más tarde adquirió otro con el mismo tema ${ }^{66}$. En 1398 el rey Noble compró en París por 1.350 francos cuatro tapices a Colin Bataille, uno de ellos con la historia de los Nueve Barones ${ }^{67}$.

Dentro de este clima literario, la peculiaridad de Olite consiste en que, en vez de limitarse a encargar obras figurativas para rememorar temas y protagonistas del ciclo artúrico, cosa que también hizo, Carlos III fabricó dentro de su palacio un castillo de Lanzarote. Allí, en un extremo de su residencia, el rey podía retirarse y revivir en su imaginación las aventuras del Caballero Blanco.

Lancelot de Navarra, el hijo del rey, tras estudiar en Toulouse fue encaminado a la carrera eclesiástica. Alcanzó las dignidades de patriarca de Alejandría y vicario administrador de la diócesis de Pamplona ${ }^{68}$. Sus armerías, talladas en los arcos que sostienen el dormitorio nuevo de la catedral pamplonesa, cuartelan las cadenas de Navarra con tres bandas que serían rojas en campo de plata ${ }^{69}$. Es decir, combina el emblema de la familia regia con el de los escudos maravillosos que la doncella entregó a Lanzarote en la aventura de la Guardia Dolorosa, de los que ya hemos hablado. Cada vez que las contemplara, don Lancelot tendría presente al caballero andante, compartiendo quizá las aficiones de su padre. Desde luego lo que compartió con total seguridad fue su gusto por edificar. Además del hermoso y costoso dormitorio alto de la catedral de Pamplona, mandó construir dos palacios que han llegado a nuestros días, en los que lamentablemente no podemos detenernos. El de Arazuri cuenta con amplias estancias dotadas de miradores que todavía mantienen las carpinterías originales. El patriarca recibió de su padre mil florines en 1418 "en ayuda de las obras que faze fazer en sus palacios de Araçur" ${ }^{\prime \prime}$. El de Pamplona, conocido hasta hace poco

64 “Aquí . iaze . seppellido . el . de . [buena . ] memoria . don . karlos . iiii . [Rey] . de . navarra . et . duc . de nemoux . desdendient . en . recta . lignea . del . emperador . sant . karlos . magno . et . de . Sant loys . Rey . de . Francia": R.S. JANKE, op. cit., 1977, p. 59.

65 Paris 1400.Les arts sous Charles VI, París, 2004, pp. 132-133 y 222-223.

66 J. LESTOCQUOY, Deux siècles de l'histoire de la tapisserie, 1300-1500, Arras, 1978, p 34.

67 J. MARTÍNEZ DE AGUIRRE, op. cit., 1987, p. 349.

68 J. GOÑI GAZTAMBIDE, Historia de los obispos de Pamplona. II. Siglos XIV-XV, Pamplona, 1979, pp. $407-467$.

69 Aunque inicialmente habíamos pensado que serían de oro y azul, para respetar la combinación de colores de los cuarteles de las armas de Carlos III (J. MARTÍNEZ DE AGUIRRE y F. MENÉNDEZ PIDAL, op. cit., 1996, p. 298), ahora no nos cabe duda de que repetirían los colores de las de Lanzarote del Lago.

70 AGNC, Caj. 105, núm. 11, 37. Sobre el palacio J.J. MARTINENA, op. cit., 2008, pp. 52-54. 
sólo por documentación, ha podido ser identificado recientemente en el ala remodelada del antiguo palacio episcopal románico ${ }^{71}$. Son suyos los miradores con asientos pétreos desde donde contemplaría el huerto de los canónigos.

Volvamos a la fase final de Olite ${ }^{72}$. ¿Es posible profundizar en los motivos que desataron una arquitectura tan particular? No se han localizado fuentes documentales al respecto. Resulta atractivo especular con una interpretación psicológica. El acuerdo sancionado con la paz de Bicêtre (2-XI-1410) estableció que los príncipes de sangre como don Carlos deberían abandonar París y regresar a sus estados. Para el rey Noble esto significó perder la proximidad a Carlos VI y la capacidad de intervención en los asuntos franceses de que había disfrutado en los últimos meses. La situación se deterioraría todavía más en el marco del conflicto abierto entre borgoñones y armañacs que determinó los principales acontecimientos de la segunda década del siglo XV (derrota catastrófica de Agincourt en 1415, asesinato de Juan sin Miedo en 1419). Nunca regresaría a París. El protagonismo que había alcanzado en la más importante corte europea se desvanecía. Durante el camino de vuelta, sin prisas, quizá esperando una regresión a la situación previa, permaneció casi todo noviembre de 1410 en Dijon, donde pudo admirar las creaciones de Sluter. Le esperaba un reino periférico, cuya vida social, cultural y artística quedaba limitada a lo que el propio monarca promoviese. ¿Acaso la fase final del palacio de Olite revela una cierta huida de la realidad mediante edificaciones que recreaban remedos de lo perdido (una vez más Vincennes) y le transportaban al mundo ideal de la caballería, de Lanzarote y la Joyosa Guarda?

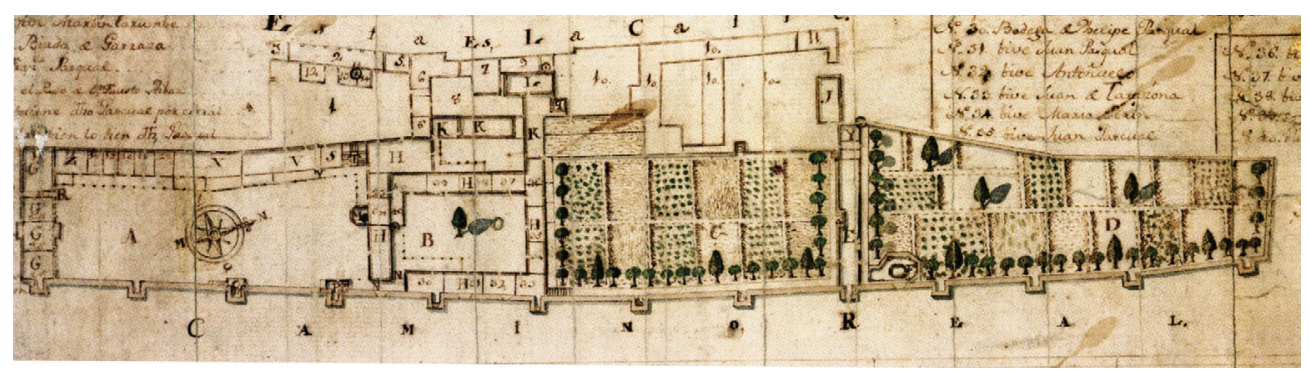

Fig. 13. Palacio de Tafalla. Plano del siglo XVIII (Archivo General de Navarra, Sec. Cartografía, no 265).

La historia de los encargos de Carlos III no termina aquí. En sus últimos años inició un nuevo palacio en Tafalla, a $5 \mathrm{~km}$ de Olite. De mayores dimensiones, complejo y costoso, sus obras avanzaron a un ritmo vertiginoso ${ }^{73}$. Una planta del siglo XVIII

71 Un documento ensalza su calidad arquitectónica: quoddam aliud notabile ac sumptuosum palacium pro usu et habitatione suis, necnon episcoporum Pampilonensium qui essent pro tempore perpetuo: J. GOÑI GAZTAMBIDE, "Nuevos documentos sobre la Catedral de Pamplona. 1. La capilla de Jesucristo y el palacio episcopal”, Príncipe de Viana, XIV (1953), doc. 5, pp. 325-326.

72 No puedo detenerme en muchos otros aspectos destacados de esta última fase, cuando introdujeron soluciones constructivas avanzadas, como los vanos en esviaje o las trompas romboidales.

73 Sobre el palacio de Tafalla: J. MARTÍNEZ DE AGUIRRE, op. cit., 1987, pp. 185-198. 
nos permite conocer su complejidad y dimensiones (fig. 13). Una diferencia sustancial con Olite consistía en que dos enormes jardines quedaban incluidos dentro un recinto torreado repartido en cuatro áreas, de más de ochocientos metros de longitud. Los aposentos se distribuían entre el patio meridional y el núcleo de edificaciones en torno a un segundo espacio enlosado. No renunció a los "exotismos" o al menos eso concluimos de los nombres de dos de sus torres: la francesa y la morisca. ¿Tuvo el rey aquí en su memoria, una vez más, Vincennes?

Para ir concluyendo, las ideas programáticas del palacio de Olite responden a un modo particular de concebir la vida regia. No estamos ante la imitación de un determinado palacio francés o castellano, aunque sabemos que Carlos III mandó a sus artífices a ambos reinos para que conocieran obras en marcha ${ }^{74}$, sino ante la materialización de un ideal de vida que fundía raíces francesas con experiencias castellanas que aquí no hemos podido desarrollar. El rey impuso su voluntad sobre condicionamientos derivados de las circunstancias espacio-temporales y de la variable disposición de medios económicos y personales. El recurso a la inspiración literaria singulariza al palacio en el panorama de la arquitectura residencial de la Europa de 1400. Desde el comienzo de su reinado Carlos III tuvo a su servicio artistas procedentes de todos los reinos vecinos: orfebres, pintores, carpinteros, tapiceros, etc. Sin embargo, la dirección de obras del palacio de Olite recayó en un navarro, Martín Périz de Estella, quien dio satisfacción a las demandas del monarca con soluciones que hemos tenido oportunidad de repasar, a veces rudimentarias, a veces imaginativas, en ocasiones deudoras de antecedentes identificables en el reino. Por eso resulta pertinente que nos preguntemos hasta qué punto pudo haber intervenido el rey no sólo en el programa sino también a la hora de dar forma al proyecto, en tareas propias del arquitecto.

Cristina de Pisan se refería a Carlos V el Sabio, paradigma vital del rey Noble, como artista diestro y sabio (droit artiste, sage artiste), entendido en geometría y diseñador de edificios (de geometrie, qui est l'art et science des mesures et des ecquerres, compas et lignes, sanz qui nulle oeuvre n'est faitte, s'entendoit souffisamment, et bien le mostroit en devisant ses ediffices), en fin, verdadero arquitecto (vray architecteur et deviseur certain et prudent ordoneur, lorsque les belles fondacions fist faire en maintes places, notables edifices beaulx et nobles, tant d'eglises comme de chasteaulx et autres bastimens a Paris et ailleurs). Philippe de Mezières llega a aludir a la "pasión" del soberano francés por las construcciones ${ }^{75}$. La indicación a mon devis e ordenança utilizada por Carlos III para referirse a sus encargos constructivos se expresa en términos semejantes a los empleados por Cristina de Pisan para Carlos V y la dinámica creativa que hemos analizado acredita una intervención equiparable de nuestro rey, al menos en Olite. Considero que no debemos escatimarle el reconocimiento de esta faceta de creatividad.

74 J. MARTÍNEZ DE AGUIRRE, op. cit., 1987, p. 95.

75 J. CHAPELOT, "Charles V maître d'ouvrage: à propos de la construction du donjon de Vincennes et de quelques chantiers contemporains", Du projet au chantier. Maîtres d'ouvrage et maîtres d'oeuvre aux XIVe-XVIe siècles, Paris, 2001, pp. 339-403, especialmente p. 373. Explicita que Carlos V intervenía en "tres niveles: la definición del proyecto, su elaboración técnica y su dirección". 
Esta vertiente constituye la cara práctica de la relevancia que otorgaba a su actividad como promotor. Su epitafio atestigua que las empresas arquitectónicas formaron parte de los méritos dignos de ser recordados. La frase "et fezo muchos notables hedificios en su regno" "76 es la más palmaria expresión de la valoración que alcanzó la promoción arquitectónica como componente de la magnificencia regia. Palacios y catedral constituyeron prendas de orgullo que cooperaron a la justificación de toda una vida y como tales formaron parte del recuerdo de la persona, condensado en el epígrafe funerario, por delante del reconocimiento de sus virtudes religiosas ${ }^{77}$. La promoción arquitectónica alcanzó con Carlos III la triple consideración de actividad digna de la realeza, medio para ennoblecer el reino y hecho memorable del individuo.

$\mathrm{Y}$ así, todavía hoy la memoria del rey permanece ligada a las singulares formas arquitectónicas del Palacio de Olite, que siguen evocando en quienes lo visitan un tiempo de caballeros andantes que nunca fue.

\footnotetext{
76 R.S. JANKE, op. cit., 1977, p. 59, transcribe el texto completo del epitafio: $\uparrow$. Aquí . iaze . seppellido . el . de . [buena . ] memoria . don . karlos . iiii ${ }^{\circ}$. [Rey] . de . navarra . et . duc . de nemoux . desdendient . en . recta . lignea . del . emperador . sant . karlos . magno . et . de . Sant loys . Rey . de . francia . Et . recobro . en . su . tempo . vna . grant . part . de . villas . et . castillos . de . su . regno . que . seyan . en . mano . del . re [y .] de . Castilla . et . sus . tierras . de . francia . que . seyan . empachadas . por . los . Reyes . de . francia . et . de . anglaterra . Este . en . su . tiempo . ennoblescio . et . exalco . en . dignidades . et . honnores . A . muchos . ricos . hombres . Cauailleros . et . fijos . dalgo . naturales . suyos . Et . fezo . muchos . notables . hedificios . en . su . regno . Et . fue . muy . piadoso . et . misericordioso Et . Regno . Rey . XXXVIII . aynnos . Et . fino . lo . viii . dia . de . septebre . del . aynno . de . mil . ccec . et xxvi.

77 En paralelo, en la cronística navarra de finales del siglo XIV y comienzos del XV la promoción arquitectónica de los reyes ocupó un lugar progresivamente destacado: J. MARTÍNEZ DE AGUIRRE, "Arquitectura y memoria en la Navarra medieval", actas del 1st International Medieval Meeting Lleida 2011, en prensa.
} 